\title{
Joint Modeling of Precipitation and Temperature Using Copula Theory for Current and Future Prediction under Climate Change Scenarios in Arid Lands (Case Study, Kerman Province, Iran)
}

\author{
T. Mesbahzadeh $\left(\mathbb{D},{ }^{1}\right.$ M. M. Miglietta $\mathbb{D}^{2},{ }^{2}$ M. Mirakbari, ${ }^{3}$ F. Soleimani Sardoo, ${ }^{4}$ \\ and M. Abdolhoseini ${ }^{5}$ \\ ${ }^{1}$ Assistant Professor, Department of Reclamation of Arid and Mountain Regions, Faculty of Natural Resources, \\ University of Tehran, Tehran, Iran \\ ${ }^{2}$ Institute of Atmospheric Sciences and Climate of the Italian National Research Council (ISAC-CNR), \\ Corso Stati Uniti 4, Padova, Italy \\ ${ }^{3}$ PhD, Faculty of Natural Resources, University of Tehran, Tehran, Iran \\ ${ }^{4}$ Academic Staff, Department of Natural Engineering, University of Jiroft, \\ Kerman and PhD Student in Faculty of Natural Resources, University of Tehran, Tehran, Iran \\ ${ }^{5} \mathrm{MSc}$, Faculty of Natural Resources, University of Tehran, Tehran, Iran
}

Correspondence should be addressed to T. Mesbahzadeh; tmesbah@ut.ac.ir

Received 5 January 2019; Accepted 21 April 2019; Published 19 June 2019

Academic Editor: Nir Y. Krakauer

Copyright (c) 2019 T. Mesbahzadeh et al. This is an open access article distributed under the Creative Commons Attribution License, which permits unrestricted use, distribution, and reproduction in any medium, provided the original work is properly cited.

\begin{abstract}
Precipitation and temperature are very important climatic parameters as their changes may affect life conditions. Therefore, predicting temporal trends of precipitation and temperature is very useful for societal and urban planning. In this research, in order to study the future trends in precipitation and temperature, we have applied scenarios of the fifth assessment report of IPCC. The results suggest that both parameters will be increasing in the studied area (Iran) in future. Since there is interdependence between these two climatic parameters, the independent analysis of the two fields will generate errors in the interpretation of model simulations. Therefore, in this study, copula theory was used for joint modeling of precipitation and temperature under climate change scenarios. By the joint distribution, we can find the structure of interdependence of precipitation and temperature in current and future under climate change conditions, which can assist in the risk assessment of extreme hydrological and meteorological events. Based on the results of goodness of fit test, the Frank copula function was selected for modeling of recorded and constructed data under RCP2.6 scenario and the Gaussian copula function was used for joint modeling of the constructed data under the RCP4.5 and RCP8.5 scenarios.
\end{abstract}

\section{Introduction}

Climate change has become a concern for the scientific community over the past two decades, due to its serious effects on humans, societies, and the environment. It is the result of changes in external forces such as fluctuation in solar cycle, volcanic eruption or increase of greenhouse gases caused by human activities, and land-use change. According to studies conducted over the past decades, global warming has caused climate change at local, regional, and global levels [1]. Global warming evidence reveals that the Earth climate has undergone significant changes between 1906 and 2005, meanwhile the temperature increased by about $0.74^{\circ} \mathrm{C}$ [2], and it is expected that by the end of the 21st century, global temperatures will increase on average between $1.81^{\circ} \mathrm{C}$ and $4^{\circ} \mathrm{C}$ [3]. These changes and their impacts on the ecosystems and lands may cause changes in global water cycle, sea level rise, drying out of lakes, penetration and mixing of saline and fresh water, and migration of species. 
The results of various climate change models have been presented to now, in the framework of the 1st Assessment Report (TAR), of the 2nd Report (FAR), of the 3rd Report (TAR), of the 4th Report, AR4 (CMIP3), and finally of the 5th Report AR5 (CMIP5) of the Intergovernmental Panel on Climate Change.

Unlike previous ones, the fifth report models emphasize the socioeconomic aspects of climate change and its role in sustainable development and risk management, and its overall framework focuses on reducing greenhouse gases and adaptation approaches to climate change. The fifth assessment report includes three working group reports and a synthesis report. The first working group's report was released in 2013, and the rest of the reports were completed in 2014. In the preparation of the fifth report which was gradually released from 2013 to 2014, the output of CMIP5 series models was used. These models use new emission scenarios called "RCP" [4]. These scenarios have four pathways, namely, RCP2.6, RCP4.5, RCP6, and RCP8.5, which are named according to their radiative forcing in 2100 [5]. Different atmospheric general circulation model runs include all or some of these scenarios.

Recently, a majority of researchers around the world have used the 5th assessment report to study climate change under new scenarios of emission in different regions [6-8]. The fifth report models have higher resolution and use newer scenarios than previous ones. In the fifth report, roughly half of the models have a spatial resolution of less than $1.3^{\circ}$, while previous reports models had a lower spatial resolution. The main difference between old and new emission scenarios is that in new ones, the radiative forcing pathway resulted from increase in greenhouse gases in the atmosphere at 2100 are measured in Watts $/ \mathrm{m}^{2}$ while in the old emission scenarios [9], just concentration pathway of greenhouse gases is specified. Climate change studies in arid and semiarid regions that are more susceptible to this phenomenon are essential to be undertaken with higher-resolution models and under new scenarios as these models provide a better understanding compared to previous models (third and fourth reports).

The general circulation models, which are the most appropriate means for predicting future climate change at global scales [10], have a coarse spatial resolution. Outputs of these models have a high spatial resolution $(250-600 \mathrm{~km})$ [11]. Therefore, the direct application of these models is not suitable for a regional or local scale; thus, their output is not proper to be used for studying the hydrological and environmental impacts of climate change at regional level [12]. The most important and suitable tool for connection between the local/regional scale and GCM large-scale is downscaling. There are various downscaling models. In general, two statistical and dynamic methods are here presented for this purpose. In the dynamic method, a numerical model with high spatial resolution, or regional climatic model, with grid spacing of about 5 to $50 \mathrm{~km}$, is coupled to the general circulation model. In statistical downscaling method, an empirical/statistical relationship is set between largescale and local variables. Using the statistical methods, global scale climatic variables, such as the mean pressure at sea level, regional wind, temperature, and geopotential height, are matched to local/regional scale variables [13]. Statistical methods are generally based on regression relationship. Among statistical downscaling methods, SDSM has been widely used for downscaling of climatic variables throughout the world [14]. SDSM combines two methods of linear multiple regression and statistical productive climate regression $[11,15]$.

The most important parameters in climate change studies are temperature and precipitation, which also play a crucial role in meteorological and hydrological phenomena such as droughts and floods. Furthermore, they are considered the most effective climate variables impacting agricultural productivity [16-18] so that the temperature affects the length of the growing season and the precipitation affects the yield $[19,20]$. Many studies have been carried out on the impacts of precipitation and temperature on agricultural products [21-24].

All of these studies found that precipitation and temperature are two factors affecting the productivity of agricultural crops. Precipitation and temperature are two climatic parameters, and the knowledge about their future trend is essential for planning natural ecosystems. The study of the pattern of temperature and precipitation changes is crucial due to climate change [25-27]. Knowing the temporal variation of temperature and its relationship with other climate variables is very important for climate planning [28]. The precipitation and temperature have very high temporal variations $[29,30]$. The dependence of precipitation to temperature causes its high variation over the time [27]. The dependence between the two parameters of temperature and precipitation [27] makes their analysis problematic when they are treated as independent of each other, since it creates errors in results of calculations.

In climate change condition, determining the interdependence relationship between two parameters of temperature and precipitation can help the assessment of the risk of extreme hydrological and meteorological phenomena; however, determining the interdependence of these parameters is difficult due to complicated dependence between them.

To determine the interdependence between precipitation and temperature, it is necessary to set the joint distribution of these two variables. In order to survey the interdependence between temperature and precipitation, determining the joint distribution of two parameters is essential. The conventional methods of calculating joint probability distribution functions of random variables have the limitation of the selection of the marginal function type, which causes error in analysis. Copula theory is a method which does not suffer from the limitations typical of multivariable distribution functions. It can be used for modeling distribution functions coupled with random variables without limitations of marginal distribution functions [31]. The copula function can be used for determining dependence between temperature and precipitation in a way that correlation calculated by this method is higher than for other methods. 
The joint modeling of precipitation and temperature can be used for providing solutions aimed at reducing the risk of extreme hydrological and meteorological events in the case of climate change in future.

Till now, there has not been a single study on the structure of interdependence between precipitation and temperature under climate change condition. The existing studies have examined the joint distribution and interdependence structure between two parameters (precipitation and temperature) in current period. Aghakouchak et al. [31] used two copula functions of Elliptical group ( $t$ and Gaussian) for two-variable analysis of temperature and precipitation. They found that fitness of $t$ copula is better than Gaussian for extreme amounts. Cong and Brady [25] specified 5 copula functions including Gumbel, T, Normal, Clayton, and Frank as the best functions for determining dependence structure between temperature and precipitation distributions.

Pandey et al. [27] determined the dependence between temperature parameters (Minimum, Maximum, Mean) and monthly precipitation using 5 copula functions including Gumbel, Frank, T, Clayton, and Normal, of which Normal distribution showed the best fit, so it was used for joint modeling of temperature and precipitation variables. Other studies on the two parameters of precipitation and temperature were also carried out by Favre et al. [32], Serinaldi [33], Schölzel and Friederichs [34], and Laux et al. [35].

In this study, changes of temperature and precipitation as two key climatic parameters influencing natural ecosystems in future in the Kerman Province (southeast Iran) are investigated in the framework of general circulation models under the $3 \mathrm{rd}$ and 5 th report scenarios. The general circulation models applied include CanESM2 of the 5th assessment report and HadCM3 of 3rd assessment report. Finally, to study interdependence between precipitation and temperature in future under climate change condition, structure of their dependency is determined under copula theory, which lacks the limitations of multivariable distribution functions in using marginal functions. Copula theory determines joint distribution of temperature and precipitation to identify interdependence of two parameters. Results of this study can be used for developing strategies in order to reduce the risk of climatic and hydrological phenomena in future.

\section{Study Area}

Kerman Province with a total area of $181716 \mathrm{~km}^{2}$ is located in southeast of Iran (Figure 1). According to Domarten climatic classification, it is considered as arid zone. The province is at the conjunction of Zagros Chain Mountain and central Iran mountains with $160 \mathrm{~km}$ length. This conjunction has created a unique environment and a specific natural status. Mean annual precipitation exceeds $143.8 \mathrm{~mm}$, maximum monthly temperature $28.7^{\circ} \mathrm{C}$, minimum monthly temperature $6.9^{\circ} \mathrm{C}$, and mean annual temperature $15.7^{\circ} \mathrm{C}$. Tables 1 and 2 present the statistical characteristics of precipitation and temperature in the area in an historical period between 1961 and 2005. In order to find changes in temperature and precipitation and their future trends, the studies conducted on the climate change in the area have just used the data of 3rd report and HadCM3 model. The studies suggest that in future, increased precipitation in winter and spring and increased temperature in the summer and fall will occur. However, no studies have been carried out to determine the structure of the interdependency between temperature and precipitation affected by the climate change using copula theory in the area, yet.

\section{Methodology}

The data used, in this study, includes precipitation and mean daily temperature in Kerman synoptic station with geographical eastern longitude of $56^{\circ} 56^{\prime}$ and northern latitude of $30^{\circ} 25^{\prime}$ and data period of 1961 to 2005, in addition to reanalysis atmospheric data (NCEP) and data belonging to two models of HadCM3 and CanESM2. Daily data are titled as predictand and NCEP predictor variables and data of general circulation model as large-scale predictor, which are available in base periods of 1961 to 2001 for the model of 3rd report and 1961 to 2005 for the model of 5th report and 2006-2100 for future runs of the 5th report and 2002 to 2099 for the 3rd report.

3.1. Downscaling of GCM Data Using SDSM. In order to review the future trend of temperature and precipitation, data of 2 models of HadCM3 and CanESM2 are converted to tiny-scale exponential data using statistical downscaling method/SDSM. In this method, a quantitative relationship is set between large-scale atmospheric variables and local surface variables such as temperature and precipitation [36]. The relationship is as follows [37]:

$$
Y=f(x) \text {, }
$$

where $Y$ is the predictor variable, $X$ is the predictand variable, and $F$ is the function of transfer, which is experimentally estimated from observational data.

Model of HadCM3 is one of the models of the 3rd evaluation report of intergovernmental panel on climate change, which has been developed by the Hadley center in England. HadCM3 model is a ocean-atmospheric system (AOGCM), whose simulations include 2 scenarios A2 and B2. The Atmospheric part of this model also includes 19 levels with spatial resolution of $2.5^{\circ}$ lat and $3.75^{\circ}$ long while the oceanic part includes 20 levels with spatial resolution of $1.25^{\circ}$ lat and $1.25^{\circ}$ long $[38,39]$. The model of CanESM2 comes from the $5^{\text {th }}$ Assessment Report of Intergovernmental Panel on Climate Change (IPCC), which includes 3 scenarios, namely, RCPP2.6, RCP4.5, and RCP8.5.

CanESM2 is an improved version of the general circulation model, developed by CCCma, which is called ESM. Effort has been made to include most of the land factors affecting the climate in the ESM modeling structure. Downscaling of the small-scale data of HadCM3 model for period of 1961-2001 and future period since 2002 to 2009 is conducted by predictor variables. Data of CanESM2 model in the base period of 1961 to 2005 and future period of 2006 


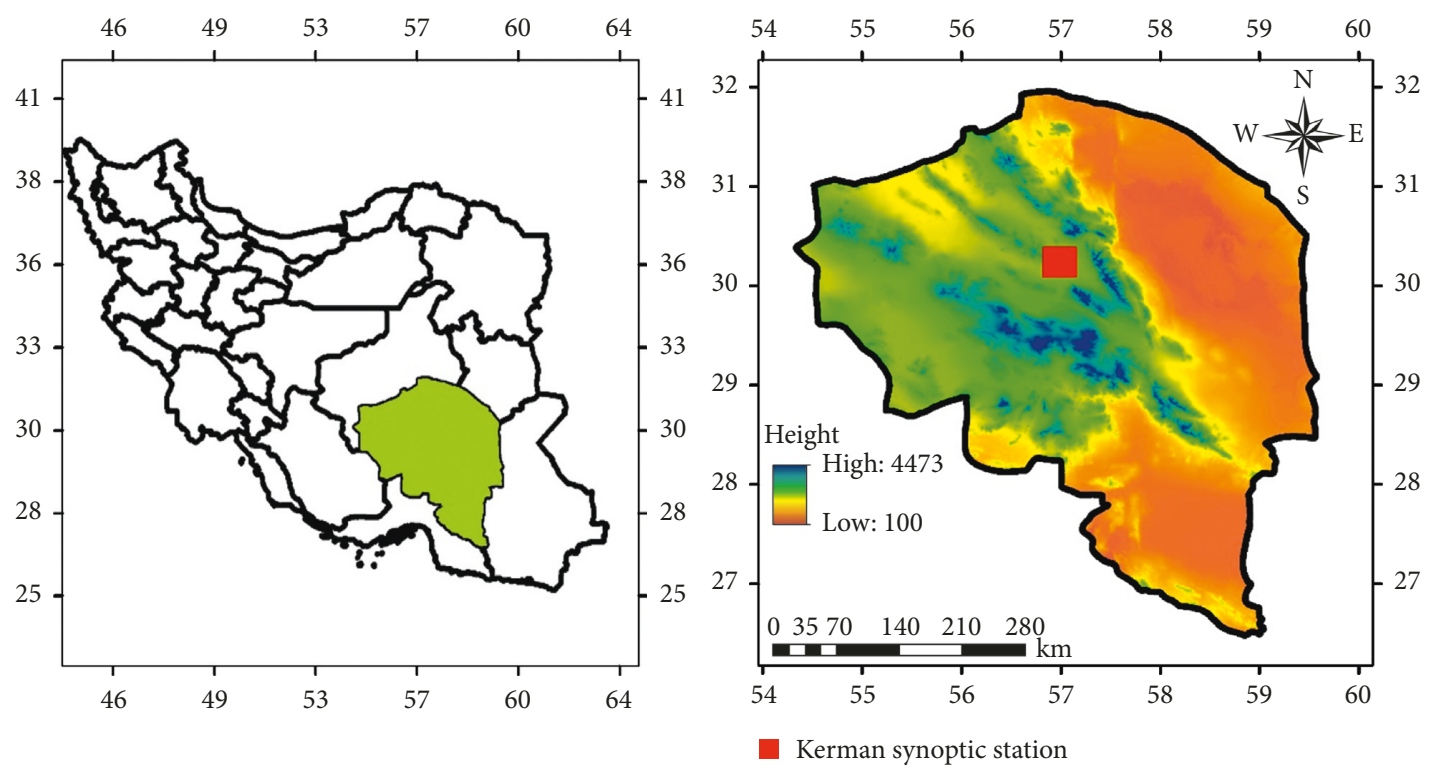

Figure 1: Location map of study area in the southeast of Iran.

TABLE 1: Statistical characteristics of monthly precipitation (1961-2005).

\begin{tabular}{|c|c|c|c|c|c|c|c|c|c|c|c|c|}
\hline Month & Jan & Feb & Mar & Apr & May & June & July & Aug & Sept & Oct & Nov & Dec \\
\hline Minimum & 0.6 & 0.3 & 3.4 & 0 & 0 & 0 & 0 & 0 & 0 & 0 & 0 & 0 \\
\hline Maximum & 97.5 & 108.4 & 73.1 & 98 & 65 & 7.8 & 11.3 & 7.4 & 6 & 23.9 & 31 & 94.2 \\
\hline Mean & 29.10 & 28.43 & 31.17 & 17.91 & 9.24 & 0.68 & 0.51 & 0.54 & 0.37 & 1.69 & 4.67 & 19.83 \\
\hline Standard deviation & 19.59 & 24.11 & 18.72 & 14.52 & 1.68 & 1.77 & 1.5 & 1.14 & 4.6 & 4.06 & 8.04 & 22.32 \\
\hline
\end{tabular}

TABLE 2: Statistical characteristics of monthly temperature (1961-2005).

\begin{tabular}{lcccccccccccc}
\hline Month & Jan & Feb & Mar & Apr & May & June & July & Aug & Sept & Oct & Nov & Dec \\
\hline Minimum & -3.12 & 1.51 & 8.16 & 13.31 & 18.23 & 23.15 & 23.57 & 21.94 & 17.9 & 11.67 & 5.5 & 1.2 \\
Maximum & 6.91 & 10.15 & 14.37 & 18 & 24.48 & 27.41 & 29.18 & 27.61 & 23.38 & 17.66 & 12.79 & 9.7 \\
Mean & 4.25 & 6.93 & 11.07 & 16.11 & 21.02 & 25.39 & 26.56 & 24.38 & 20.76 & 15.58 & 9.74 & 5.85 \\
Standard deviation & 1.93 & 1.71 & 1.47 & 1.48 & 1.24 & 1.04 & 1.43 & 1.41 & 1.54 & 1.47 & 1.52 & 1.77 \\
\hline
\end{tabular}

to 2100 are converted to small-scale data using predictor variables and SDSM. This method has 4 key steps, which includes determining predictor variable of NCEP, model calibration, model verification, and simulation of data relating mean temperature and precipitation under old and new emission scenarios.

3.2. Copula Theory. In order to identify the interdependence structure between temperature and precipitation, the joint distribution of two variables is determined using copula theory. The theory was presented for multivariable probability modeling by Sklar (1959) [40]. Copula function provides the opportunity to combine several single-variable distributions in various families of one, two, or multivariable distributions considering the interdependence of the variables. In other words, copula function $C\left(u_{1}, u_{2}, \ldots u_{N}\right)$ is a conjunctive function to link random variable distribution functions of $X_{1}, X_{2}, \ldots, X_{\mathrm{N}}$ with marginal functions of $F x_{1}\left(X_{1}\right), F x_{2}\left(X_{2}\right) \ldots, F X_{N}\left(X_{N}\right)$ [41]. According copula theory, joint distribution of two variables of mean temperature $(X)$ and precipitation $(Y)$ is as follows:
$F\left(x_{1}, x_{2}, \ldots, x_{N}\right)=C_{\theta}\left[F_{X_{1}}\left(x_{1}\right), F_{X_{2}}\left(x_{2}\right), \ldots, F_{X_{N}}\left(X_{N}\right)\right]$.

Copula functions are multivariate distributions with uniform marginal functions, which model interdependence between several variables [41]. The most important advantage of using copula functions is that the structure of dependency between variables can be defined even if marginal functions are different; this means that in order to set (define) a joint distribution function having equal marginal functions for each variable is not necessary. Other types of probability distributions carry out the modeling of interdependence of variable structures assuming that functions of marginal functions are equal, but this assumption causes error in multivariable analysis. By copula theory, marginal functions are selected for setting multivariable functions as well as defining nonlinear and asymmetric relationship between variables. Copula function includes a variety of families such as: Elliptical ( $\mathrm{t}$ copula, Normal), Archimedean (Gumbel, Clayton, Frank, Ali- Mikhail-Haq), Extreme Value (Husler-Reiss, Galambos, Tawn, and t-EV, 
Gumbel) and other families, namely, Plackett and FarlieGumbel-Morgenstern [42]. Families of Archimedean and Elliptical are used mostly [43]. Archimedean family has two symmetric and asymmetric forms, which, respectively, have one parameter and more than 2 parameters. Elliptical family, unlike Archimedean family, does not follow a specific shape but its advantage is the dependence between upper and lower tails.

Interdependence structure of random variables determines the type of copula function used for joint modeling. According to Huang et al. [44], interdependence of temperature and precipitation during the various months is negative or positive. Then, joint modeling of temperature and precipitation is different depending on the structure of interdependency between variables. As a result, in the case that interdependence is positive, various families of functions such as Archimedean, Elliptical, and other types of copula functions can be used. Unlikely, for negative interdependence values, a minor number of functions are usable. In this research, due to negative relationship between precipitation and mean temperature data, symmetric Archimedean functions such as Rotated Clayton, Rotated Joe, Frank, Rotated Gamble, and also Elliptical of Gaussian are used for joint modeling (Table 3).

3.3. Estimation of Parameters of Copula Function. In order to estimate the parameters of copula function, both the parametric and nonparametric methods are used. In parametric method, relationship between generator function of each copula and Kendall coefficient (equation (3)) is used [45] (Table 3). In this equation, $c$ and $d$ are the number of pairs of concordant and discordant variables and $n$ is number of observations. Two pairs of variables $\left(X_{i}\right.$, $\left.Y_{i}\right)$ and $\left(X_{j}, Y_{j}\right)$ are concordant if $X_{j}>X_{i}$ and $Y_{j}>Y_{i}$ or $X_{i}>X_{j}$ and $Y_{i}>Y_{j}$. They are also considered discordant when $X_{i}>X_{j}$ and $Y_{j}>Y_{i}$ or $X_{j}>X_{i}$ and $Y_{i}>Y_{j}$. Alternatively, if $\left(X_{i}-X_{j}\right)\left(Y_{i}-Y_{j}\right)>0$, variables are concordant, and if $\left(X_{i}-X_{j}\right)\left(Y_{i}-Y_{j}\right)<0$, variables are discordant. In the parametric method, using the maximum log-likelihood function (equation (4)), parameter of $\theta$ is estimated [32]. Log-likelihood function estimates parameter of $\theta$ using density copula function. If dependent random variables are as $x_{1 k}, x_{2 k}, \ldots, x_{p k}(k=1, \ldots, n)$ with copula function of $F_{\theta}\left(x_{1 k}, \ldots, x_{p k}\right)=C_{\theta}\left(F_{1}\left(X_{1 k}\right), \ldots, F_{p}\left(X_{p k}\right)\right)$, loglikelihood function is defined as follows [32]:

$$
\begin{aligned}
\tau & =\frac{(c-d)}{\left(\begin{array}{c}
n \\
2
\end{array}\right)}, \\
L(\theta) & =\sum_{k=1}^{n} \log \left[c_{\theta}\left\{F_{1}\left(x_{1 k}\right), \ldots, F_{p}\left(x_{p k}\right)\right\}\right],
\end{aligned}
$$

where $c_{\theta}$ is the copula density function; $\mathrm{F}$ is the marginal distribution function; and $x_{1 k}, x_{2 k}, \ldots, x_{p k} k=1, \ldots, n$ are the dependent random variables.
3.4. Goodness of Fit Test for Copula Function. Before modeling by copula functions, the copula function having the best fit is selected. For selecting the best copula function, value of joint empirical probability of two variables of precipitation and temperature is calculated through empirical copula (equation (5)) and then is compared with the values resulted from copula functions (Archimedean and Elliptical families). To compare empirical copula with each copula functions, normalized root mean square error (NRMSE) and Nash-Sutcliffe coefficient were selected (equations (6) and (7)). Also, two criteria, namely, Akaike Information Criterion (AIC) and Bayesian Information Criterion (BIC) (equations (8) and (9)) [46, 47], are used. In these equations, the empirical probability of precipitation and mean temperature is $v$ and $u, P_{e i}$ is the value of empirical copula, $P_{i}$ is the value of copula theory, $K$ is the model parameter, $n$ is the number of observations, and $L$ is the value of maximum log-likelihood function.

$$
\begin{aligned}
C_{n}(u, v) & =\frac{1}{n} \sum_{t=1}^{n} 1\left(U_{t}<u, V_{t}<v\right), \\
\mathrm{NRMSE} & =\sqrt{\frac{1}{n} \sum_{i=1}^{n} \frac{\left(P_{e i}-P_{i}\right)^{2}}{\left(P_{e i, \max }-P_{e i, \min }\right)},} \\
\mathrm{NSE} & =1-\frac{\sum_{n=1}^{N}\left(P_{e i}-P_{i}\right)^{2}}{\sum_{n=11}^{N}\left(P_{e i}-\bar{P}_{e i}\right)^{2}}, \\
\mathrm{AIC} & =2 k-2 \ln (L), \\
\mathrm{BIC} & =2 n \log L+k \log (n) .
\end{aligned}
$$

\section{Results}

4.1. Downscaling GCM Data. After reviewing and controlling the quality of the observational data, the NCEP predictor variables, which have the highest correlation with each observational data, were selected. The number of NCEP variables for temperature as an unconditional parameter is less than that for precipitation, which is a conditional variable (due to including zero-precipitation days) (Table 4). NCEP variables have been estimated for models of GCM for two periods of 1961-2001 and 1961-2005 (Table 2).

The model calibration and verification steps were undertaken based on NCPE variables for both models in the base period. In order to increase the accuracy of the model, various values of variance inflation factor were selected for temperature and precipitation parameters and bias correction was applied for precipitation. Later, based on the results of the model verification exercise, the best value of each factor was determined through statistical comparison. In this way, variance inflation factors of temperature and precipitation and also bias correction factors of precipitation were determined as 6, 10, and 1, respectively. Figure 2 shows efficiency of SDSM model for downscaling precipitation and 
TABle 3: Different types of copula functions.

\begin{tabular}{lcccc}
\hline & & Joint CDF & $\theta$ & Kendall $\tau$ \\
\hline & Frank & $C(u, v ; \theta)=1 / \theta \ln \left[1+\left(e^{-\theta u}-1\right)\left(e^{-\theta v}-1\right) / e^{-\theta}-1\right]$ & $R /\{0\}$ & $1-(4 / \theta)\left(1-D_{1}(\theta)\right)$ \\
Archimedean & $\begin{array}{c}\text { Rotated Joe } \\
\text { family }\end{array}$ & $1-\left[1-\prod_{i=1}^{m}\left(1-\left(1-u_{i}\right)^{\theta}\right)\right]^{1 / \theta}$ & $(-\infty,-1)$ & $-1-4 \int x / x^{k} \int_{0}^{x} t^{k} /(\exp (t)-1) d t$ \\
& $\begin{array}{l}\text { Rotated } \\
\text { Gumbel }\end{array}$ & $C(u, v ; \theta)=u+v-1+C(1-u, 1-v)$ & $(-\infty,-1)$ & $-1-(1 / \theta)$ \\
& $\begin{array}{l}\text { Rotated } \\
\text { Clayton }\end{array}$ & $C(u, v ; \theta)=u+v-1+C(1-u, 1-v)$ & $(-\infty, 0)$ & $\theta /(2-\theta)$ \\
\hline Elliptical family & Gaussian & $C(u, v)=\int_{0}^{u} \Phi\left(\Phi^{-1}(v)-\rho x y \Phi^{-1}(t) / \sqrt{1-\rho^{2} x y}\right) d t$ & $(-1,+1)$ & $(2 / \pi) \arcsin (\theta)$ \\
\hline
\end{tabular}

TABLE 4: NCEP variables for two periods (1961-2001 and 1961-2005).

\begin{tabular}{|c|c|c|c|}
\hline & Predictand & \multicolumn{2}{|c|}{ NCEP variable } \\
\hline \multirow{6}{*}{$1961-2001$} & \multirow{5}{*}{ Precipitation } & Ncepp5thas & $500 \mathrm{hPa}$ wind direction \\
\hline & & Ncepr500as & 500 hpa relative humidity \\
\hline & & Ncepr850as & 850 hpa relative humidity \\
\hline & & Nceprhumas & Near surface relative humidity \\
\hline & & Ncepshumas & Surface specific humidity \\
\hline & Temperature & Ncepptemas & Mean temperature at $2 \mathrm{~m}$ \\
\hline \multirow{5}{*}{$2005-1961$} & \multirow{4}{*}{ Precipitation } & Ncepp500gl & 500 hpa geopotential \\
\hline & & Ncepprcpgl & Accumulated precipitation \\
\hline & & Nceps500gl & 500 hpa specific humidity \\
\hline & & Ncepshumgl & 1000 hpa specific humidity \\
\hline & Temperature & Ncepptempgl & Screen air temperature \\
\hline
\end{tabular}

temperature data in two base periods of 1961-2001 and 1961-2005, respectively, for two models of HadCM3 and CanESM2. Generally, because of consistency of temperature data, this efficiency is higher for temperature in comparison to precipitation. Finally, large-scale data of HadCM3 and CanESM2 were downscaled under SERA and RCP scenarios using SDSM method for precipitation and mean temperature in future (2017-2100).

4.2. Assessment of Efficiency and Uncertainty of Model. Statistical criteria of Nash-Sutcliffe index and NRMSE were calculated in order to assess downscaled values of precipitation and mean temperature by NCEP variables and large-scale (HadCM3 and CanSM2) models for the period of 1961-2001 and 1961-2005 (Table 5). The results display that downscaled values of mean temperature have a higher accuracy compared to precipitation in both GCM models. Given existence of so many zeroes in precipitation data series, data do not follow normal distribution, so accuracy of modeling precipitation decreases in comparison to temperature. Furthermore, values relating to the assessment criteria of precipitation data modeled by CanESM2 (5th Report) have further compliance with observed data in comparison to values estimated by HadCM3. The data of mean temperature modeled by GCM have nearly equal compliance with the observed data. Therefore, in order to joint modeling of precipitation and mean temperature, values calculated by CanESM2 are used.

In order to study the trend of climatic parameters in future period compared to the base period, the MannKendall test was applied for precipitation and mean temperature data modeled by CanESM2 (Table 6). Based on the Mann-Kendall test, observed and modeled precipitation do not follow any meaningful trend under RCP2.6 and RCP8.5 scenarios. However, data produced by RCP4.5 scenario shows a decreasing trend. The results of the Mann-Kendall test on mean temperature showed the series modeled by RCP scenarios and observed data have an increasing trend, and the increase in the data modeled under scenario of RCP8.5 is higher. The results of modeling of precipitation data under scenario of RCP showed that mean annual precipitation in future based on RCP2.6, RCP4.5, and RCP8.5 scenarios will be $157.2 \mathrm{~mm}, 148.1 \mathrm{~mm}, 190.2 \mathrm{~mm}$, respectively, which in comparison with the observation period $(143.8 \mathrm{~mm})$, an increase would be seen in the study area (Figure 3). Also, the results of modeling of mean temperature data under scenario of RCP showed mean annual temperature in future based on RCP2.6, RCP4.5, and RCP8.5 scenarios will be $16.9^{\circ} \mathrm{C}, 17.4^{\circ} \mathrm{C}$, and $18.2^{\circ} \mathrm{C}$, respectively, which in comparison with the observation period (equal to $15.6^{\circ} \mathrm{C}$ ), an increase would be seen in the study area (Figure 3). 

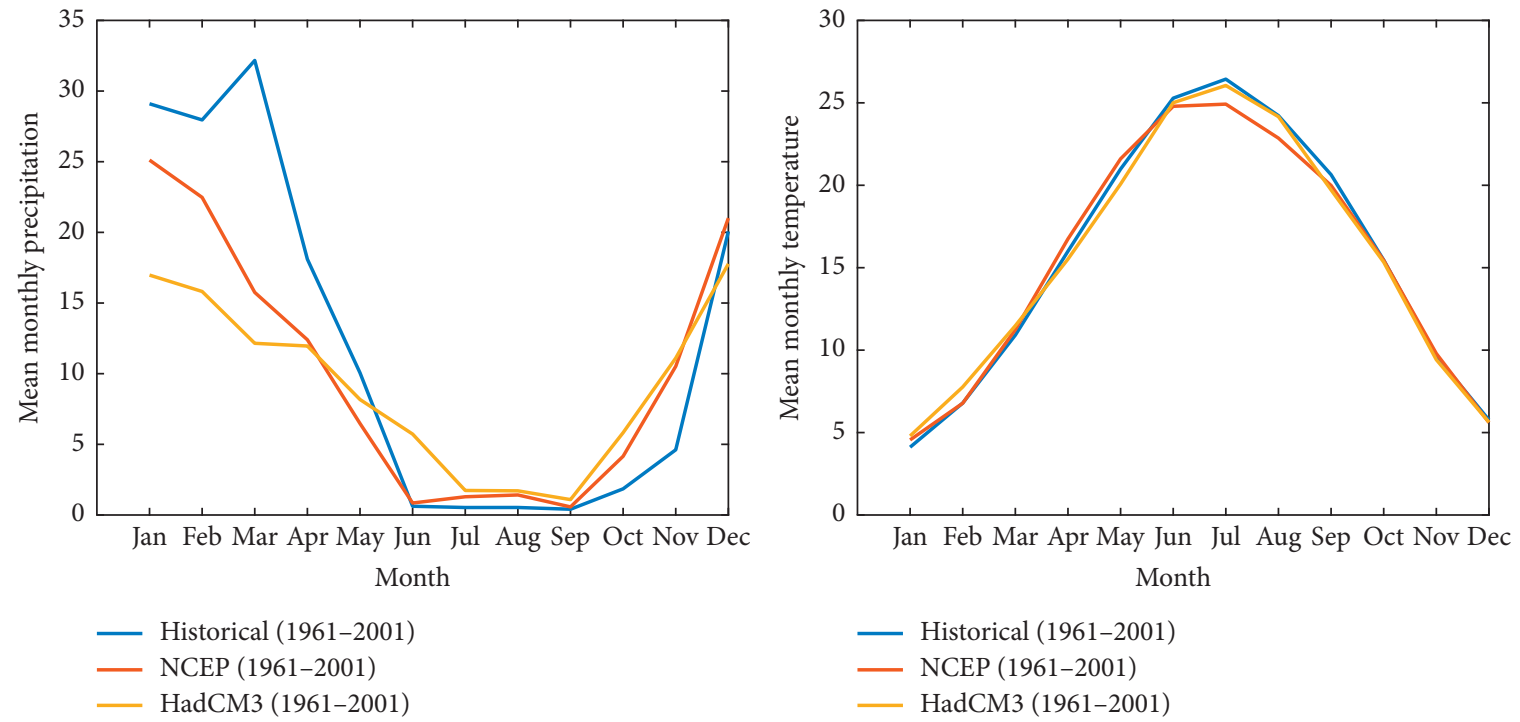

(a)
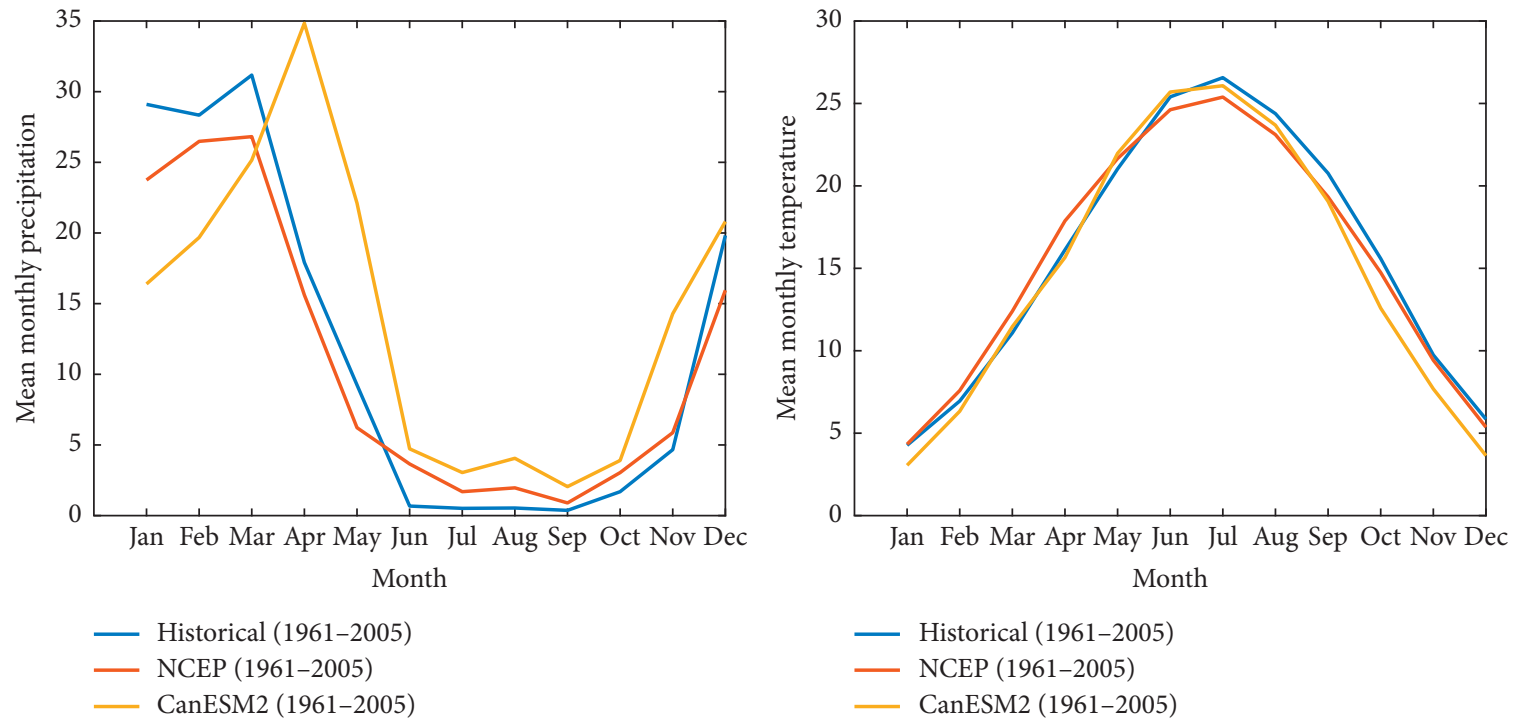

(b)

FIgure 2: Comparison of downscaled data using predictor variables (NCEP and GCM models) with the historical precipitation and temperature for (a) 1961-2001 (HadCM3) and (b) 1961-2005 (CanESM2).

TABle 5: Evaluation criteria of downscaled data for HadCM3 and CanESM2 models.

\begin{tabular}{lcccc}
\hline Predicted & Predictor & NSE & NRMSE & Correlation \\
\hline \multirow{4}{*}{ Precipitation } & NCEP & 0.946 & 0.0259 & 0.99 \\
& CanESM2 & 0.551 & 0.057 & 0.84 \\
& HadCM3 & 0.458 & 0.0829 & 0.67 \\
\hline \multirow{3}{*}{ Temperature } & NCEP & 0.9824 & 0.0094 & 0.9923 \\
& CanESM2 & 0.984 & 0.0053 & 0.998 \\
& HadCM3 & 0.964 & 0.0133 & 0.991 \\
\hline
\end{tabular}

Figure 4 shows error bar of mean monthly precipitation data. Error data are used for displaying deviation of data. Based on RCP scenario, mean precipitation in future in the months Jan, Feb, Mar, Apr, and Dec would fall down and in
TABLE 6: The results of Mann-Kendall test for historical and modeled data under RCP scenarios.

\begin{tabular}{|c|c|c|c|}
\hline \multicolumn{2}{|c|}{ Parameter } & $Z$ value & $P$ value \\
\hline \multirow{4}{*}{ Precipitation } & Historical & -0.988 & 0.323 \\
\hline & RCP2.6 & 0.341 & 0.733 \\
\hline & $\mathrm{RCP} 4.5$ & -2.476 & 0.013 \\
\hline & RCP8.5 & 1.37 & 0.169 \\
\hline \multirow{4}{*}{ Temperature } & Historical & 4.77 & 0.000 \\
\hline & RCP2.6 & 2.46 & 0.014 \\
\hline & RCP4.5 & 9.4 & 0.000 \\
\hline & RCP8.5 & 11.87 & 0.000 \\
\hline
\end{tabular}

other months would go up. The error bar of mean monthly temperature shows an increase throughout the year. The increase rate in warm months of May to August will be 


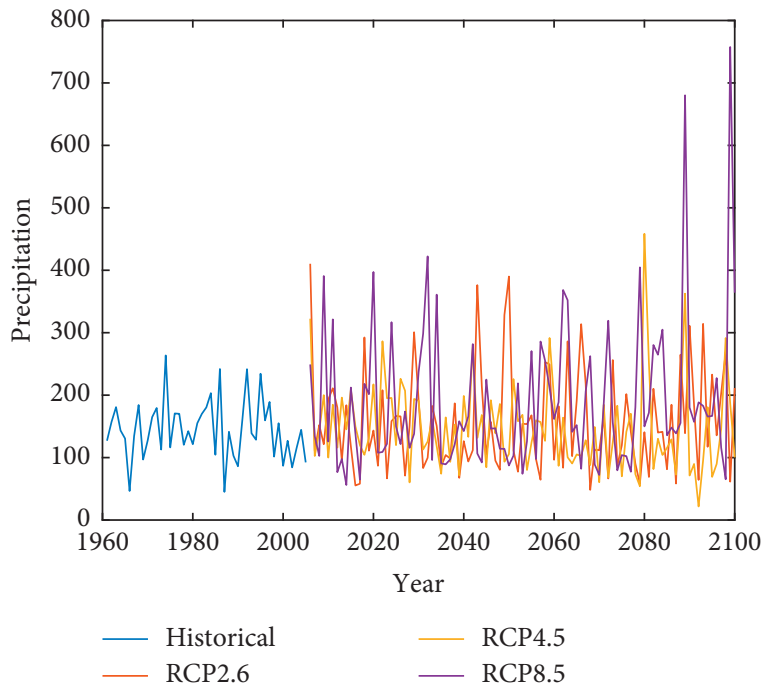

(a)

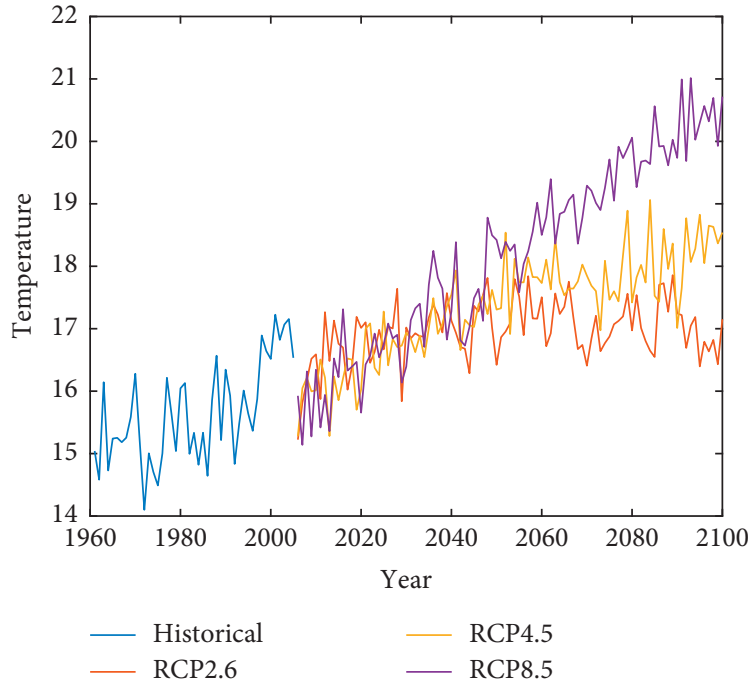

(b)

Figure 3: Comparison of precipitation (a) and temperature (b) observed and modeled under RCP scenarios during the period 1961-2100.

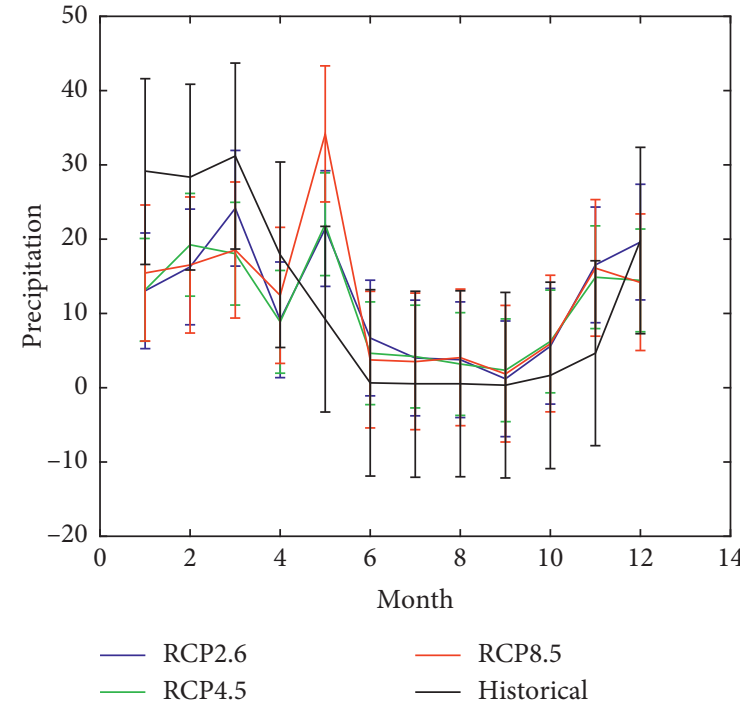

(a)

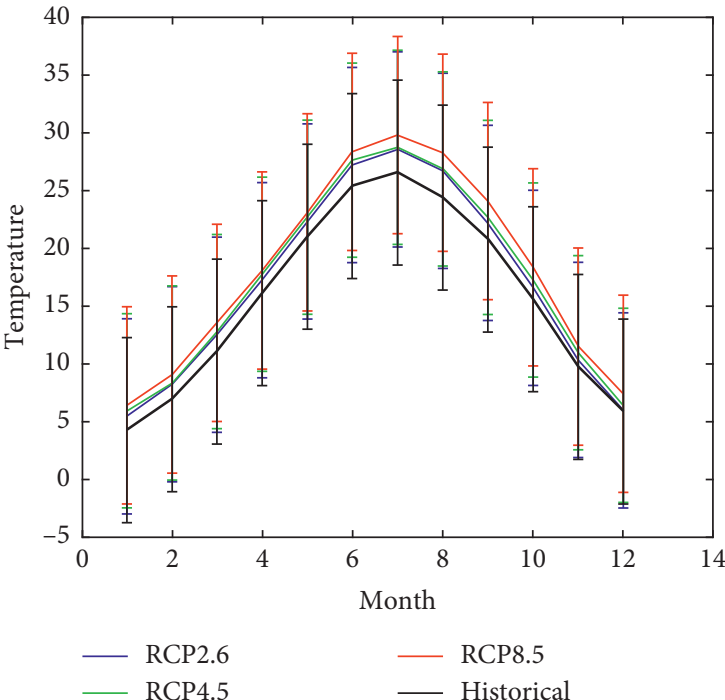

(b)

FiguRE 4: Error bar of mean monthly precipitation (a) and temperature (b) in historical and future periods.

higher than in other months. On the contrary, the increase rate will be less between October and December (Figure 4).

\subsection{Determining Interdependence Structure of Precipitation and Mean Temperature in Two Historical and Future Periods}

4.3.1. Marginal Functions of Temperature and Precipitation. In order to provide a joint modeling of temperature and precipitation, correlation between the variables was estimated using the Kendall rank correlation coefficient. Kendall correlation was selected because the data do not follow a normal distribution. Table 7 displays the Kendall correlation coefficient of monthly precipitation and mean temperature for the historical period and the future. The Kendall correlation coefficient amounts show that the relationship between precipitation and temperature is different in various months, so in the historical period, there is a meaningful negative correlation in March, April, May, and September. The meaningful relationship between temperature and precipitation under RCP2.6 and RCP4.5 scenarios in April and May is negative, and in other months, there is no meaningful relationship. Meanwhile, there is a negative meaningful relationship in April and May and a meaningful positive relationship in August between precipitation and temperature in future under RCP8.5. Then, the amounts of precipitation and temperature in April which show the highest correlation were selected for joint modeling in the 
TABLE 7: Kendall correlation coefficient $(\tau)$ and $P$ value for mean temperature and precipitation in historical and future periods.

\begin{tabular}{lccccccccccccc}
\hline & & Jan & Feb & Mar & Apr & May & June & July & Aug & Sept & Oct & Nov & Dec \\
\hline \multirow{2}{*}{ Historical } & $\tau$ & -0.12 & -0.03 & $-\mathbf{0 . 2 1}$ & $-\mathbf{0 . 4 3}$ & $-\mathbf{0 . 4 3}$ & -0.15 & 0.16 & 0.02 & $\mathbf{0 . 2 3}$ & -0.09 & 0.02 & -0.08 \\
& $P$ value & 0.22 & 0.74 & $\mathbf{0 . 0 3}$ & $\mathbf{0 . 0 0 0}$ & $\mathbf{0 . 0 0 0}$ & 0.19 & 0.17 & 0.82 & $\mathbf{0 . 0 4}$ & 0.42 & 0.82 & 0.42 \\
\hline \multirow{2}{*}{ RCP2.6 } & $\tau$ & 0.02 & 0.02 & -0.07 & $\mathbf{- 0 . 4 4}$ & $-\mathbf{0 . 2 7}$ & -0.09 & -0.06 & -0.005 & 0.07 & 0.12 & 0.08 & -0.04 \\
& $P$ value & 0.73 & 0.78 & 0.28 & $\mathbf{0 . 0 0 0}$ & $\mathbf{0 . 0 0 0}$ & 0.22 & 0.36 & 0.94 & 0.35 & 0.07 & 0.23 & 0.5 \\
\hline \multirow{2}{*}{ RCP4.5 } & $\tau$ & 0.02 & -0.05 & -0.07 & $\mathbf{- 0 . 3 4}$ & $\mathbf{- 0 . 2 2}$ & -0.08 & 0.07 & -0.07 & -0.004 & -0.001 & -0.003 & -0.02 \\
& $P$ value & 0.72 & 0.47 & 0.31 & $\mathbf{0 . 0 0 0}$ & $\mathbf{0 . 0 0 1}$ & 0.3 & 0.32 & 0.31 & 0.96 & 0.98 & 0.95 & 0.72 \\
\hline \multirow{2}{*}{ RCP8.5 } & $\tau$ & -0.03 & -0.02 & -0.08 & $-\mathbf{0 . 3 1}$ & $\mathbf{- 0 . 2 7}$ & -0.09 & 0.07 & $\mathbf{0 . 2 2}$ & 0.08 & 0.09 & -0.03 & 0.13 \\
& $P$ value & 0.58 & 0.69 & 0.2 & $\mathbf{0 . 0 0 0}$ & $\mathbf{0 . 0 0 0}$ & 0.21 & 0.28 & $\mathbf{0 . 0 0 5}$ & 0.26 & 0.21 & 0.64 & 0.06 \\
\hline
\end{tabular}

TABLE 8: Marginal distribution functions and selection of the best copula for joint modeling of temperature and precipitation in historical and future periods.

\begin{tabular}{|c|c|c|c|c|}
\hline & \multicolumn{2}{|r|}{ Precipitation } & \multicolumn{2}{|r|}{ Temperature } \\
\hline & Distribution & Parameters & Distribution & Parameters \\
\hline $\begin{array}{l}\text { Historical } \\
\text { RCP2.6 } \\
\text { RCP } 4.5 \\
\text { RCP } 8.5\end{array}$ & $\begin{array}{l}\text { Wakeby } \\
\text { Johnson SB } \\
\text { Wakeby } \\
\text { Wakeby }\end{array}$ & $\begin{array}{c}\alpha=21.99, \beta=0.1191, \gamma=0, \delta=0, \xi=-1.734 \\
\gamma=0.91, \delta=0.50, \lambda=38.6, \zeta=-24.2 \\
\alpha=8.59, \beta=0.177, \gamma=1.69, \delta=0.38, \xi=-0.706 \\
\alpha=12.93, \beta=0.082, \gamma=0, \delta=0, \xi=-1.29\end{array}$ & $\begin{array}{c}\text { Weibul } \\
\text { Wakeby } \\
\text { Beta } \\
\text { Wakeby }\end{array}$ & $\begin{array}{c}\alpha=12.82, \beta=16.67 \\
\alpha=12.1, \beta=5.35, \gamma=1.48, \delta=-0.21, \xi=14.1 \\
\alpha 1=6.74, \alpha 2=4.17, a=9.88, b=22.6 \\
\alpha=55.86, \beta=24.3, \gamma=5.44, \delta=-0.89, \xi=13.05\end{array}$ \\
\hline
\end{tabular}

historical and the future period. The marginal distribution of precipitation and temperature was determined through fitting 20 univariate distribution based on KolmogorovSmirnov and chi-square tests. Based on statistical tests, Wakeby distribution was selected for precipitation data in historical period and under RCP4.5 and RCP8.5 and Johnson SB distribution for the modeled data under RCP2.6. Also, Wakeby distribution was selected for temperature data in historical period and under RCP2.6 and RCP8.5 scenarios and Beta distribution for the data under RCP4.5 scenario (Table 8).

4.4. Selecting the Best Copula for Joint Modeling of Temperature and Precipitation in Historical and Future Periods. In order to fit copula functions to precipitation and temperature variables, the parameters of copulas were estimated using parametric and nonparametric methods for historical and future periods (Table 9). Parameters of copula function present structure of dependency between temperature and precipitation variables. Based on the results of the selection criteria of the best fit of copula function for precipitation and temperature in historical and future climate, among 5 copulas, Frank copula function was selected for joint modeling in historical and future periods under scenario of RCP2.6 and Gaussian copula function under scenarios of RCP4.5 and RCP8.5 (Table 9). Figure 5 shows Q-Q plots of Frank and Gaussian copula functions for historical data and the modeled under RCP scenarios. High correlation between theoretical and empirical copula suggests fitness of Frank and Gaussian functions for joint modeling of temperature and precipitation. Figure 6 shows the values of probability density of Gaussian and Frank copula functions in historical and the future period. The values of joint probability density of precipitation and temperature show these variables have symmetric correlation in upper and lower tails; this is one of the specifications of Frank and Gaussian copula functions
[48]. In other words, random variables which follow Frank and Gaussian copula functions lack correlation in upper and lower tails. The structure of dependence between precipitation and temperature in historical and future periods under RCP2.6 scenario is equal. The structure of dependence of these variables under RCP4.5 and RCP8.5 is equal as well.

4.5. Joint Probability of Precipitation and Temperature for Two Historical and Future Periods. Joint probability of precipitation and mean temperature is very important for management and assessment of the risk imposed by extreme meteorological and hydrological events as well as management of productivity of agricultural products. Joint probability is defined as the probability when precipitation and temperature simultaneously exceed a certain value which is shown as $(P(U \geq u, V \geq v))$. Awareness of this probability can be useful in establishment of an early warning system for extreme events such as flood and drought. Joint probability of precipitation and mean temperature based on copula theory is defined as follows [49]:

$$
P(U \geq u, V \geq v)=1-F_{U}(u)-F_{V}(v)+C\left(F_{U}(u), F_{V}(v)\right) .
$$

Awareness that the probability of precipitation and temperature simultaneously exceeds a certain value is also useful for improving water resources systems under climate change condition in future. For example, probability that, simultaneously, precipitation exceeds its maximum value $(\operatorname{Pr}(U \geq 98))$ and temperature exceeds the temperature corresponding to maximum precipitation $(\operatorname{Pr}(V \geq 18))$ is 0.007 (Figure $7(\mathrm{a}))$. Also, the probability that, simultaneously, temperature exceeds its maximum value $(\operatorname{Pr}(U \geq 19.55))$ and precipitation exceeds the precipitation corresponding to maximum temperature $(\operatorname{Pr}(V \geq 0))$ is 0.004 (Figure $7(\mathrm{a}))$. According 
TABLE 9: Selection criteria of the best fit of copula functions for historical and future periods.

\begin{tabular}{|c|c|c|c|c|c|c|c|c|c|c|c|}
\hline & \multirow{2}{*}{ Copula functions } & \multicolumn{5}{|c|}{ Parametric } & \multicolumn{5}{|c|}{ Nonparametric } \\
\hline & & AIC & $\mathrm{BIC}$ & NRMSE & NSE & Parameter & AIC & $\mathrm{BIC}$ & NRMSE & NSE & Parameter \\
\hline \multirow{5}{*}{ Historical } & Gaussian & -17.1 & -15.3 & 0.039 & 0.93 & -0.589 & -17 & -15.2 & 0.038 & 0.91 & -0.597 \\
\hline & Frank & -18.8 & -17.7 & 0.038 & 0.94 & -4.84 & -18.8 & -17 & 0.037 & 0.93 & -4.613 \\
\hline & Rotated Clayton & -10.6 & -8.87 & 0.041 & 0.92 & -0.918 & -7.37 & -5.57 & 0.043 & 0.90 & -1.518 \\
\hline & Rotated Gumbel & -14.9 & -13.1 & 0.039 & 0.93 & -1.61 & -14.3 & -12.5 & 0.038 & 0.91 & -1.759 \\
\hline & Rotated Joe & -10.5 & -8.73 & 0.043 & 0.92 & -1.74 & -5.95 & -4.41 & 0.045 & 0.89 & -2.395 \\
\hline \multirow{5}{*}{$\mathrm{RCP} 2.6$} & Gaussian & -41.3 & -40.1 & 0.032 & 0.96 & -0.602 & -41.2 & -39.2 & 0.035 & 0.94 & -0.578 \\
\hline & Frank & -44.6 & -42.3 & 0.027 & 0.97 & -3.99 & -44.5 & -42.2 & 0.032 & 0.95 & -4.06 \\
\hline & Rotated Clayton & -32.5 & -30.1 & 0.043 & 0.95 & -0.992 & -21.5 & -19.8 & 0.048 & 0.91 & -1.29 \\
\hline & Rotated Gumbel & -37.9 & -35.4 & 0.044 & 0.95 & -1.56 & -36.8 & -33.1 & .0 .05 & 0.90 & -1.64 \\
\hline & Rotated Joe & -26.9 & -23.1 & 0.069 & 0.92 & 1.674 & -17.7 & -15.6 & 0.078 & 0.91 & -2.18 \\
\hline \multirow{5}{*}{$\mathrm{RCP} 4.5$} & Gaussian & -17.7 & -15.3 & 0.020 & 0.9 & -0.524 & -17.2 & -16.8 & 0.022 & 0.9 & -0.517 \\
\hline & Frank & -16.1 & -14.8 & 0.022 & 0.97 & -3.40 & -16.4 & -15.2 & 0.024 & 0.95 & -3.45 \\
\hline & Rotated Clayton & -10.6 & -10.6 & 0.028 & 0.96 & -0.851 & -10.4 & -7.53 & 0.032 & 0.94 & -1.057 \\
\hline & Rotated Gumbel & -14.3 & -14.4 & 0.021 & 0.97 & -1.46 & -14.7 & -13 & 0.031 & 0.92 & -1.52 \\
\hline & Rotated Joe & -9.95 & -8.15 & 0.032 & 0.95 & -1.54 & -9.98 & -6.55 & 0.038 & 0.91 & -1.95 \\
\hline \multirow{5}{*}{ RCP8.5 } & Gaussian & -19 & -18.1 & 0.023 & 0.95 & -0.463 & -19 & -17.8 & 0.024 & 0.94 & -0.469 \\
\hline & Frank & -15.2 & -13.2 & 0.024 & 0.94 & -2.8 & -14.9 & -12.3 & 0.024 & 0.92 & -3.04 \\
\hline & Rotated Clayton & -14.1 & -11.1 & 0.025 & 0.91 & -0.548 & -9.64 & -8.12 & 0.025 & 0.9 & -0.903 \\
\hline & Rotated Gumbel & -16.2 & -14.3 & 0.026 & 0.93 & -1.39 & -15.9 & -13.5 & 0.027 & 0.91 & -1.45 \\
\hline & Rotated Joe & -11.7 & -9.8 & 0.031 & 0.87 & -1.53 & -9.32 & -8.5 & 0.032 & 0.84 & -1.81 \\
\hline
\end{tabular}

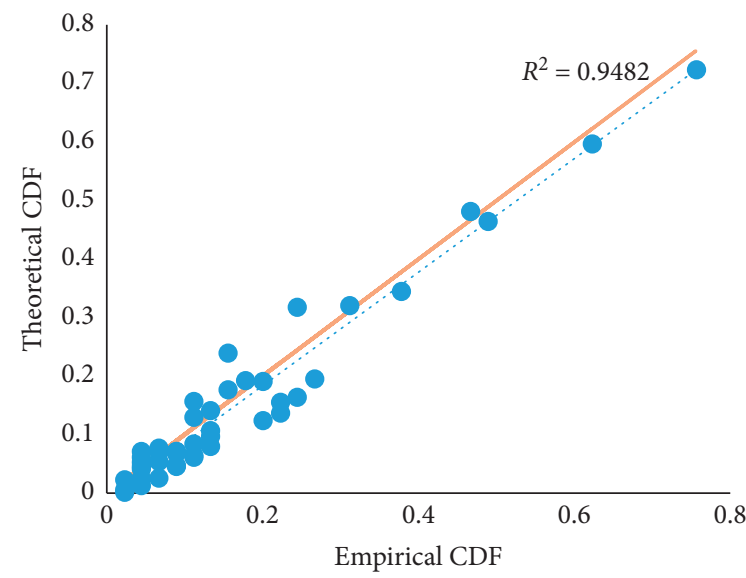

(a)

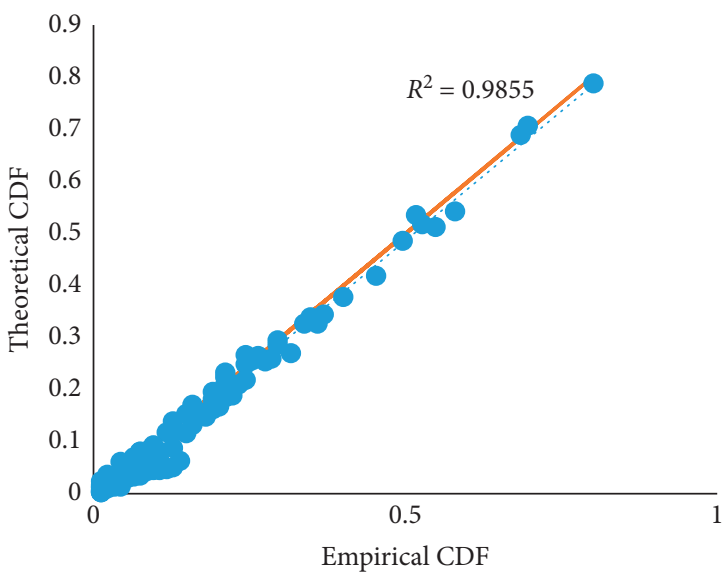

(c)

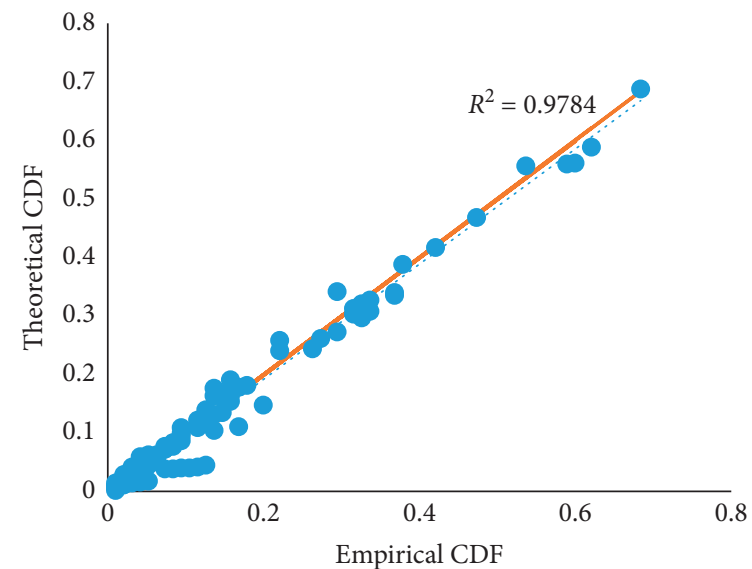

(b)

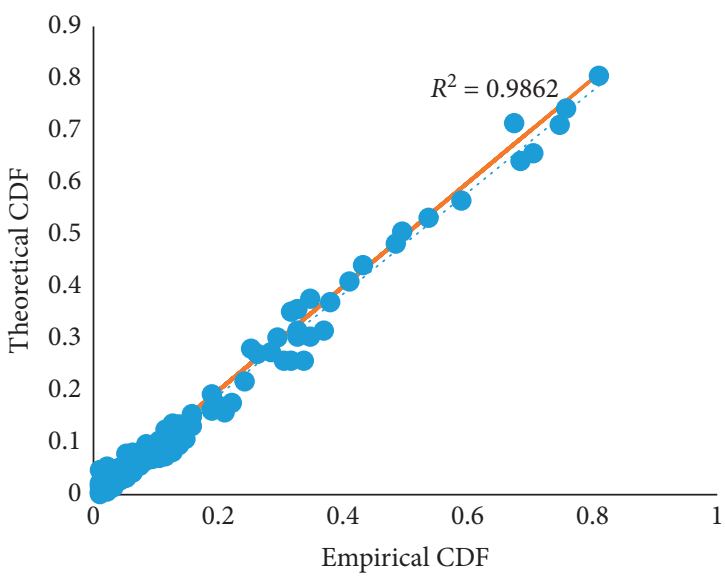

(d)

Figure 5: Q-Q plot for (a) historical data, (b) modeled data under RCP2.6, (c) modeled data under RCP4.5, and (d) modeled data under RCP8.5. 

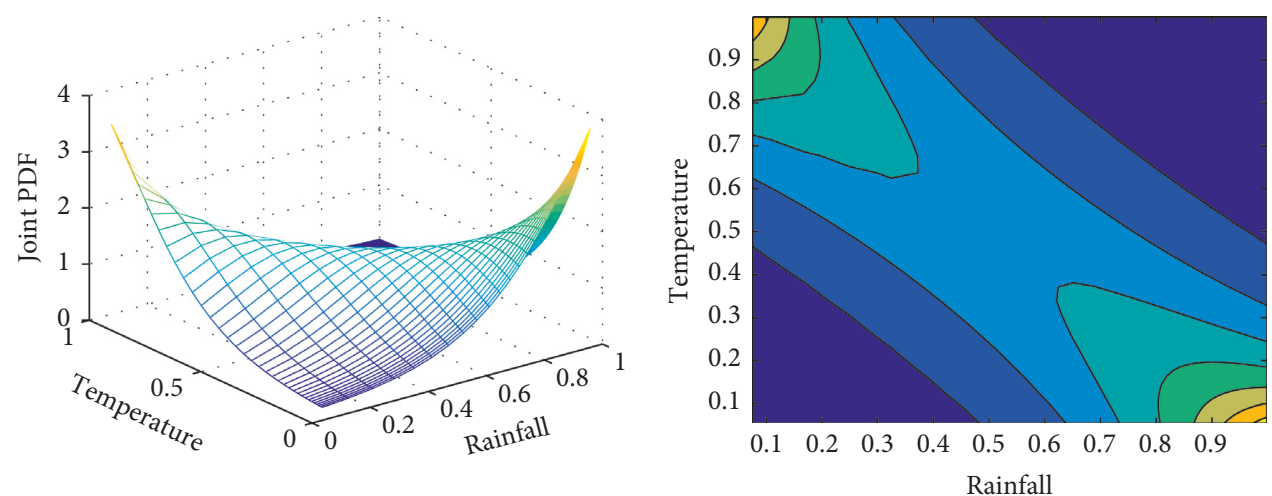

(a)
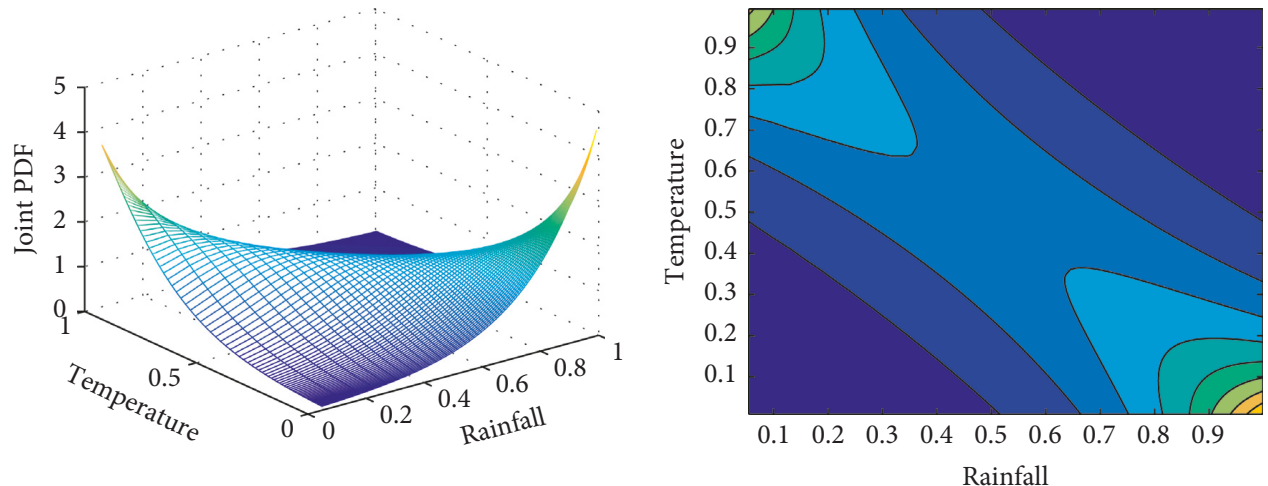

(b)
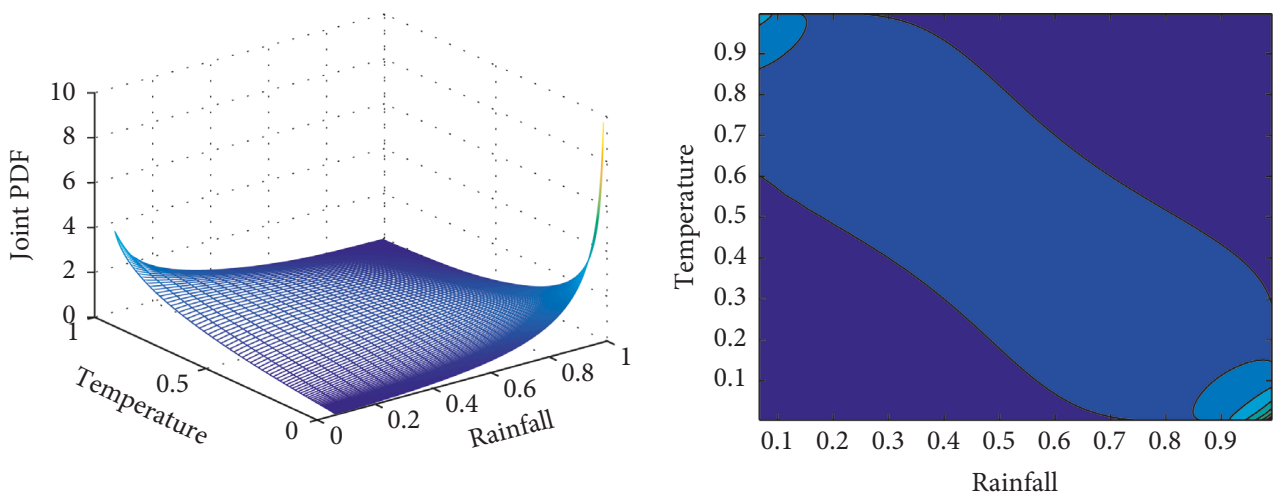

(c)
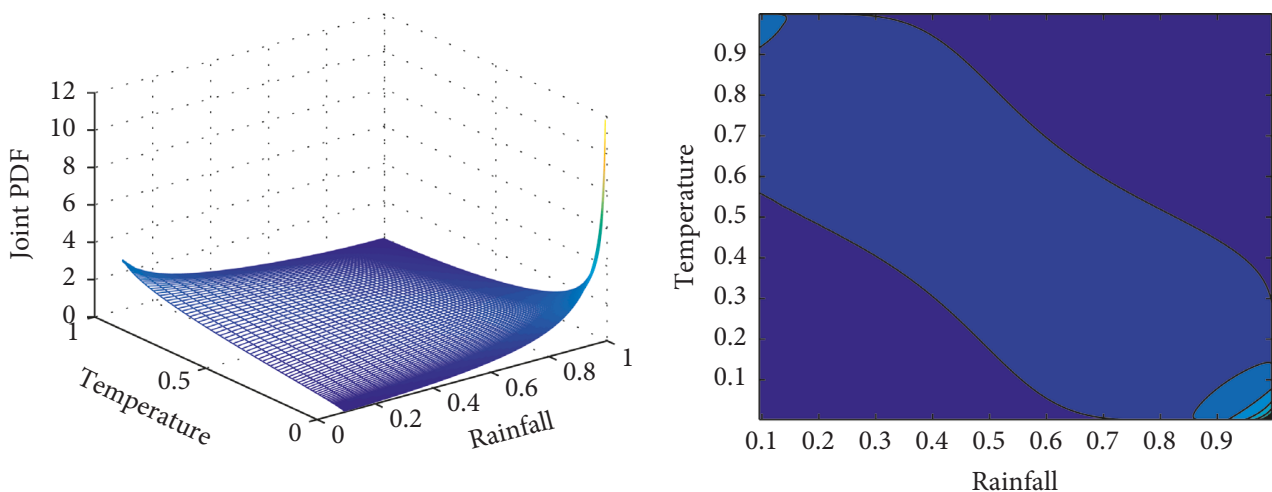

(d)

FIGURE 6: The joint PDF and corresponding contour lines for (a) historical period, (b) RCP2.6, (c) RCP4.5, and (d) RCP8.5. 

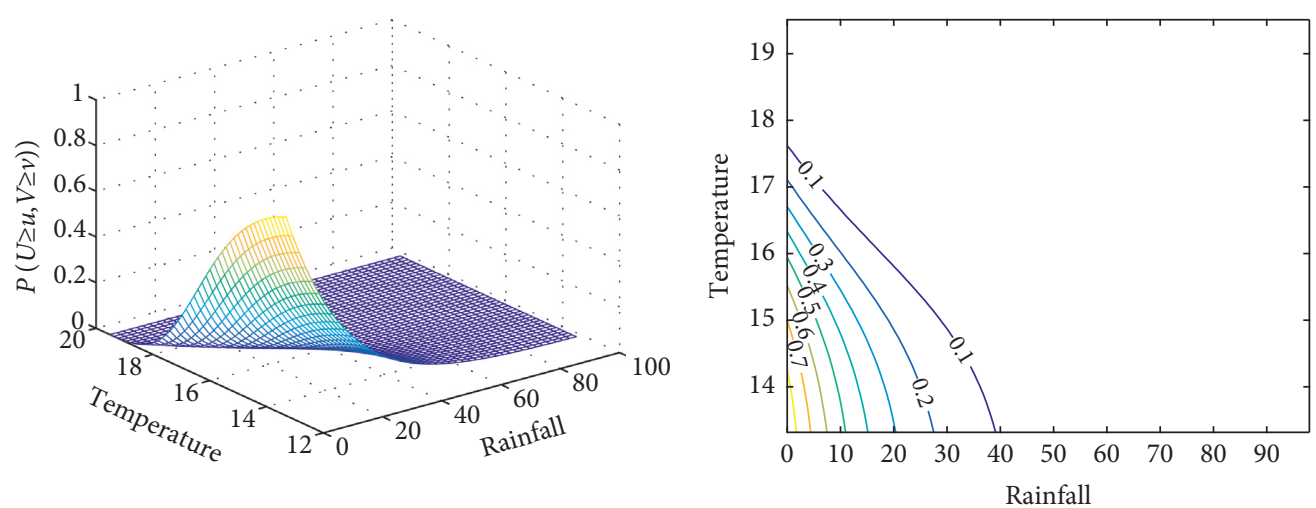

(a)
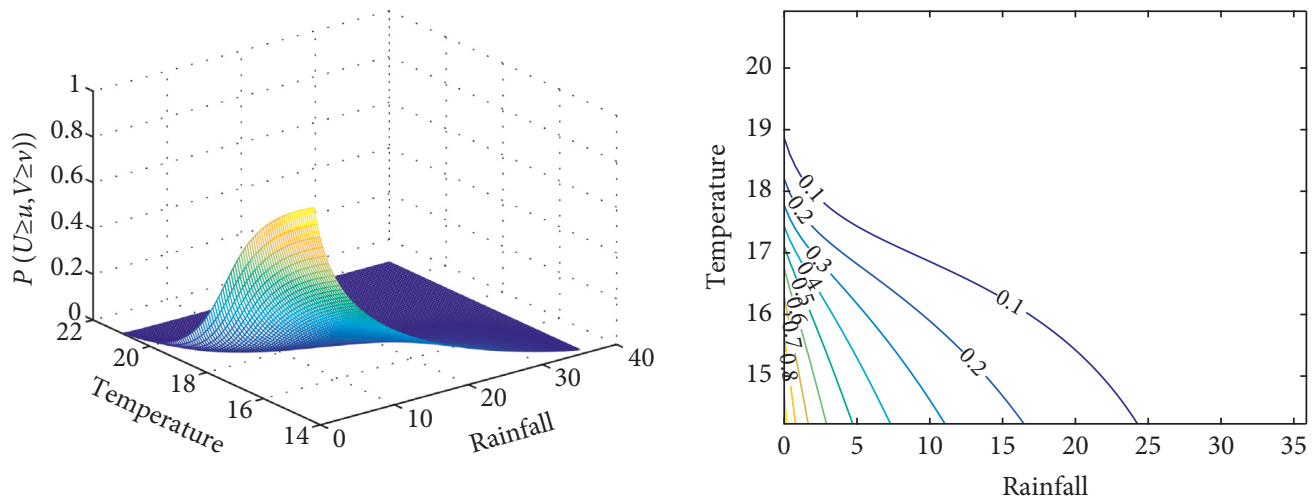

(b)
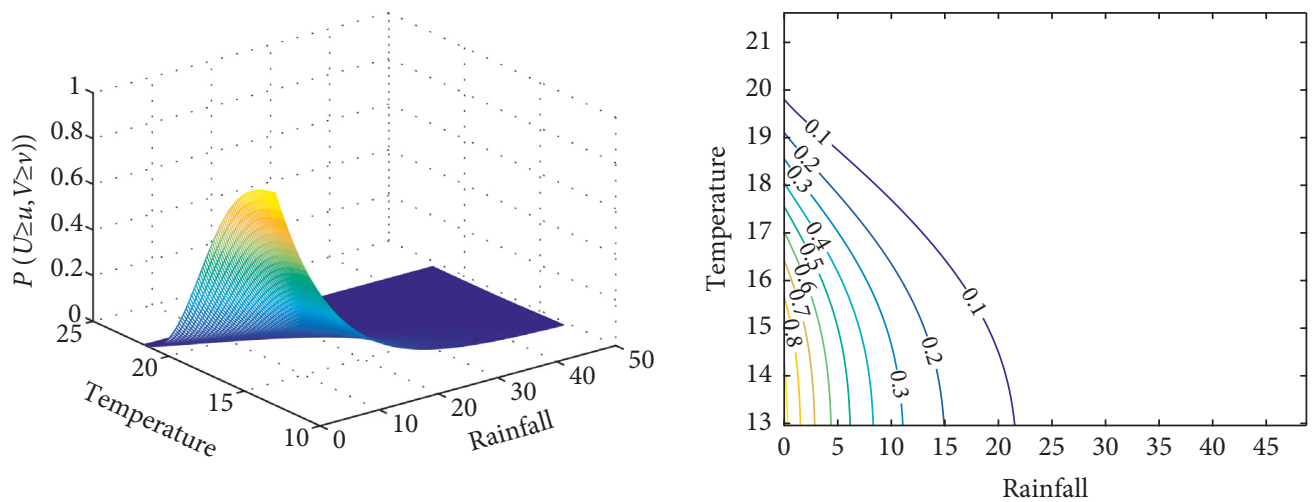

(c)
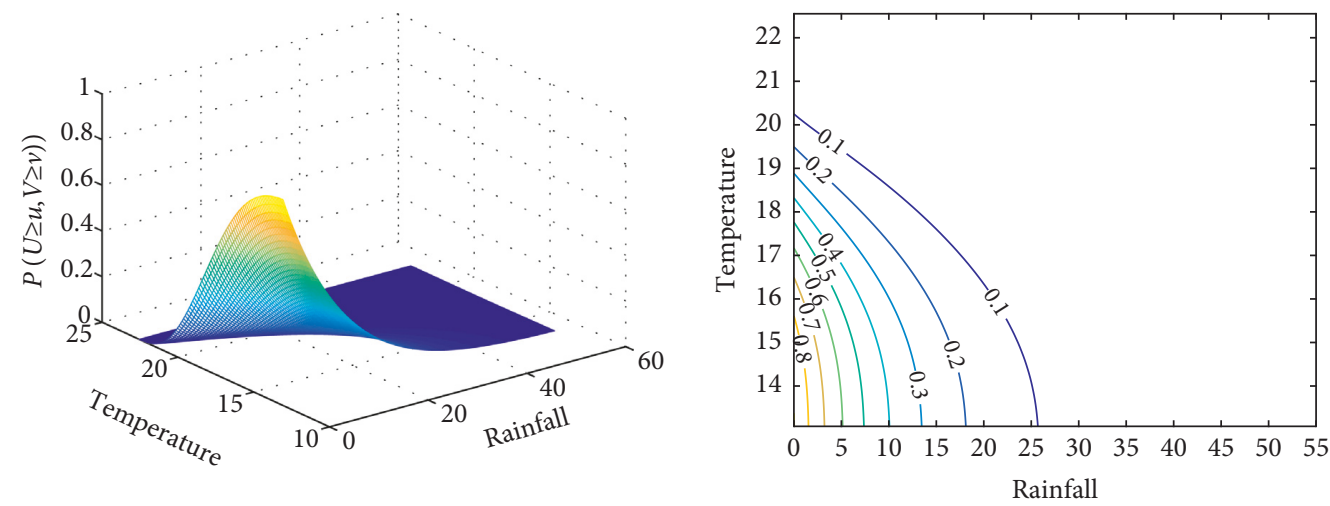

(d)

FIgURE 7: The joint probability $\operatorname{Pr}(U \geq u, V \geq v)$ of precipitation and temperature for historical (a) and future (b) RCP2.6, (c) RCP4.5, and (d) RCP8.5. 
to the modeled data under RCP2.6 scenario, probability that, simultaneously, precipitation exceeds its maximum value $(\operatorname{Pr}(U \geq 35.86))$ and temperature exceeds the temperature corresponding to maximum precipitation $(\operatorname{Pr}(V \geq 15.76))$ is 0.006 . Also, probability that precipitation $(\operatorname{Pr}(U \geq 6.4))$ and temperature $(\operatorname{Pr}(V \geq 20.92))$ simultaneously exceeding the maximum temperature and its corresponding precipitation is 0.004 (Figure 7(b)). Based on the amounts modeled under RCP4.5 scenario, probability that precipitation $(\operatorname{Pr}(U \geq 48.75))$ and temperature $(\operatorname{Pr}(V \geq 15.36))$ simultaneously exceeding maximum precipitation and its corresponding temperature is 0.0034 . Also, probability that precipitation and temperature simultaneously exceeding the maximum temperature $(\operatorname{Pr}(V \geq$ $21.61))$ and its corresponding precipitation $(\operatorname{Pr}(U \geq 2.33))$ is 0.0005 (Figure $7(\mathrm{c})$ ). Based on the modeled data under RCP8.5, probability that precipitation and temperature simultaneously exceeding maximum precipitation $(\operatorname{Pr}(U \geq 55))$ and its corresponding temperature $(\operatorname{Pr}(V \geq 15.61))$ is 0.002 . Also, probability that precipitation and temperature simultaneously exceeding the maximum temperature $(\operatorname{Pr}(V \geq 22.55))$ and its corresponding precipitation $(\operatorname{Pr}(U$ $\geq 0)$ ) is 0.0002 (Figure $7(\mathrm{~d})$ ). According to this, probability that precipitation and temperature simultaneously exceeding maximum precipitation and its corresponding temperature in historical period is higher than the future period. Furthermore, probability that precipitation and temperature exceeding the maximum temperature and its corresponding precipitation in historical period is higher than in the future period under climate change condition.

\section{Conclusion}

In this study, copula theory was used for joint modeling of precipitation and temperature which are two main climatic factors impacting agricultural production and meteorological and hydrological phenomena such as flood and drought in climate change condition. Increase or decrease of climatic parameters such as precipitation and temperature impacts on extreme events. Knowing the pattern of temporal change of temperature and its relationship with other climatic parameters is essential for climatic planning for future. Global warming in recent years has been reported using climate change models by many researchers. The fifth assessment report issued by IPCC, despite the former reports, has focused on socioeconomic aspects of climate change and its impact on sustainable development and risk management when its general framework underlines greenhouse reduction and adaptation with the climate change. These models have higher resolution and use new emission scenarios in comparison to the older reports. In this study, in order to compare the 5th report with the former ones, two models of HadCM3 and CanESM2 were used for reviewing the trends of precipitation and temperature change in future under new and old scenarios. The results of the modeled precipitation and temperature show that CanESM2 has more compliance with the observed data which is because of higher resolution of the 5th report models. Based on the modeled data under RCP scenarios, the study area shows temperature and precipitation will increase in future.

Interdependence between temperature and precipitation is such that their independent analysis will cause errors in estimations. Dependence of precipitation to temperature causes its significant change over the time. In climate change condition, determining the relationship of interdependence between precipitation and temperature can help assessing risk associated with extreme hydrological and meteorological phenomena. Aiming at finding the interdependence of precipitation and temperature, it is needed to determine the joint distribution of these variables. For this purpose, copula theory has been used for joint modeling of temperature and precipitation in climate change condition. According to the results of applying selection criteria of the best fit, Frank copula function for historical and modeled data under RCP2.6 scenario and Gaussian copula function for modeled data under RCP4.5 and RCP8.5 scenarios were selected for joint analyzing temperature and precipitation. The presented results of joint modeling are in line with previously published research. For instance, Cong and Brady [25], Keerthirathne and Perera [18], and [50] indicated two Frank and Gaussian copulas for joint modeling of precipitation and temperature [48].

Frank and Gaussian copula functions show that data in the historical and future periods have symmetric dependence in upper and lower tails. Frank and Gaussian copula functions were used for joint modeling in the historical and future periods. Awareness that precipitation and temperature simultaneously exceed a certain value is very useful for improving water resources systems under climate change condition in future. The joint probability values showed that the probability of simultaneously exceeding temperature and precipitation with respect to the maximum precipitation and its corresponding temperature is higher in historical period than that in the future period under climate change. In addition, the probability that precipitation and temperature exceed the maximum temperature and its corresponding precipitation in historical period is higher than that in future under climate change condition. As a whole, joint modeling of precipitation and temperature for future under climate change condition can be used towards providing risk reduction strategies for extreme meteorological and hydrological events.

\section{Data Availability}

The data used to support the findings of this study are included within the article.

\section{Conflicts of Interest}

The authors declare that they have no conflicts of interest.

\section{References}

[1] R.-1. Li and S. Geng, "Impacts of climate change on agriculture and adaptive strategies in China," Journal of Integrative Agriculture, vol. 12, no. 8, pp. 1402-1408, 2013. 
[2] H. Tabari, S. Marofi, A. Aeini, P. H. Talaee, and K. Mohammadi, "Trend analysis of reference evapotranspiration in the western half of Iran," Agricultural and Forest Meteorology, vol. 151, no. 2, pp. 128-136, 2011.

[3] Z. Wang, D. L. Ficklin, Y. Zhang, and M. Zhang, "Impact of climate change on streamflow in the arid Shiyang River Basin of northwest China," Hydrological Processes, vol. 26, no. 18, pp. 2733-2744, 2012.

[4] R. H. Moss, J. A. Edmonds, K. A. Hibbard et al., "The next generation of scenarios for climate change research and assessment," Nature, vol. 463, no. 7282, pp. 747-756, 2010.

[5] D. P. Van Vuuren, J. Edmonds, M. Kainuma et al., "The representative concentration pathways: an overview," Climatic Change, vol. 109, no. 1, pp. 5-31, 2011.

[6] R. Chadwick, I. Boutle, and G. Martin, "Spatial patterns of precipitation change in CMIP5: why the rich do not get richer in the tropics," Journal of Climate, vol. 26, no. 11, pp. 38033822, 2013.

[7] V. V. Kharin, F. W. Zwiers, X. Zhang, and M. Wehner, "Changes in temperature and precipitation extremes in the CMIP5 ensemble," Climatic Change, vol. 119, no. 2, pp. 345-357, 2013.

[8] P. Kumar Bal, A. Ramachandran, R. Geetha et al., "Climate change projections for Tamil Nadu, India: deriving highresolution climate data by a downscaling approach using PRECIS," Theoretical Applied and Climatology, vol. 123, no. 3-4, pp. 523-535, 2016.

[9] C. $\mathrm{H} . \mathrm{Xu}$ and $\mathrm{Y} . \mathrm{Xu}$, "The projection of temperature and precipitation over China under RCP scenarios using a CMIP5 multi-model ensemble," Atmospheric and Oceanic Science Letters, vol. 5, no. 6, pp. 527-533, 2012.

[10] C. Miao, Q. Duan, Q. Sun, and J. Li, "Evaluation and application of Bayesian multi-model estimation in temperature simulations," Progress in Physical Geography: Earth and Environment, vol. 37, no. 6, pp. 727-744, 2013.

[11] S. Y. B. Gebremeskel, L. F. de Smedt, L. Hoffmann, and L. Pfister, "Analysing the effect of climate changes on stream flow using statistically downscaled GCM scenarios," International Journal River Basin Management, vol. 2, no. 4, pp. 271-280, 2005.

[12] L. E. Hay, R. L. Wilby, and G. H. Leavesley, "A comparison of delta change and downscaled Gcm scenarios for three mountainous basins in the United States1," JAWRA Journal of the American Water Resources Association, vol. 36, no. 2, pp. 387-397, 2000.

[13] F. A. Wetterhall, D. Bárdossy, S. H. Chen, and C. Y. Xu, "Daily precipitation downscaling techniques in three Chinese regions," Water Resources Research, vol. 42, article W11423, 2006.

[14] J. Huang, J. Zhang, Z. Zhang, C. Xu, B. Wang, and J. Yao, "Estimation of future precipitation change in the Yangtze River basin by using statistical downscaling method," Stochastic Environmental Research and Risk Assessment, vol. 25, no. 6, pp. 781-792, 2011.

[15] R. L. Wilby, P. G. Whitehead, A. J. Wade, D. Butterfield, R. J. Davis, and G. Watts, "Integrated modelling of climate change impacts on water resources and quality in a lowland catchment: River Kennet, UK," Journal of Hydrology, vol. 330, no. 1-2, pp. 204-220, 2006.

[16] L. Chen, V. P. Singh, S. Guo, A. K. Mishra, and J. Guo, "Drought analysis using copulas," Journal of Hydrologic Engineering, vol. 18, no. 7, pp. 797-808, 2013.
[17] D. J. Dupuis, "Using copulas in hydrology: benefits, cautions, and issues," Journal of Hydrologic Engineering, vol. 12, no. 4, pp. 381-393, 2007.

[18] D. G. T. C. Keerthirathne and K. Perera, "Joint Distribution of rainfall and temperature in Anuradhapura, Srilanka using copulas," in Proceedings of the International Research Symposium on Engineering Advancements, (RSEA 2015) SAITM, Malabe, Sri Lanka, 2015.

[19] P. Cantelaube and J.-M. Terres, "Seasonal weather forecasts for crop yield modelling in Europe," Tellus A: Dynamic Meteorology and Oceanography, vol. 57, no. 3, pp. 476-487, 2005.

[20] J. E. Olesen and M. Bindi, "Consequences of climate change for European agricultural productivity, land use and policy," European Journal of Agronomy, vol. 16, no. 4, pp. 239-262, 2002.

[21] P. Cooper, J. Dimes, K. Rao, B. Shapiro, B. Shiferaw, and S. Twomlow, "Coping better with current climatic variability in the rain-fed farming systems of sub-Saharan Africa: an essential first step in adapting to future climate change?," Agriculture Ecosystems and Environment, vol. 126, no. 1-2, pp. 24-35, 2008.

[22] W. Erskine and F. El Ashkar, "Rainfall and temperature effects on lentil (Lens culinaris) seed yield in Mediterranean environmentsffects on lentil (Lens culinaris) seed yield in Mediterranean environments," Journal of Agricultural Science, vol. 121, no. 3, pp. 347-354, 1993.

[23] D. Lobell and C. Field, "Global scale climate-crop yield relationships and the impacts of recent warming," Environmental Research Letters, vol. 2, no. 1, article 014002, 2007.

[24] R. Muchow, T. Sinclair, and M. Bennett, "Temperature and solar-radiation effects on potential maize yield across locations," Agronomy Journal, vol. 82, no. 2, pp. 338-343, 1999.

[25] R.-G. Cong and M. Brady, "The interdependence between rainfall and temperature: copula analyses," Scientific World Journal, vol. 2012, pp. 1-11, 2012.

[26] J. Kreyling and C. Beier, "Complexity in climate change manipulation experiments," Bioscience, vol. 63, no. 9, pp. 763-767, 2013.

[27] P. K. Pandey, L. Das, D. Jhajharia, and V. Pandey, "Modelling of interdependence between rainfall and temperature using copula," Modeling Earth Systems and Environment, vol. 4, no. 2, pp. 867-879, 2018.

[28] S. Balyani, Y. Khosravi, F. Ghadami, M. Naghavi, and A. Bayat, "Modeling the spatial structure of annual temperature in Iran," Modeling Earth Systems and Environment, vol. 3, no. 2, pp. 581-593, 2017.

[29] L. F. Buba, N. U. Kura, and J. B. Dakagan, "Spatiotemporal trend analysis of changing rainfall characteristics in Guinea Savanna of Nigeria," Modeling Earth Systems and Environment, vol. 3, no. 3, pp. 1081-1090, 2017.

[30] R. Sethi, B. K. Pandey, R. Krishan, D. Khare, and P. C. Nayak, "Performance evaluation and hydrological trend detection of a reservoir under climate change condition," Modeling Earth Systems and Environment, vol. 1, no. 4, 2015.

[31] A. AghaKouchak, A. B. Bardossy, and E. Habib, "Copulabased uncertainty modelling: application to multisensor precipitation estimates," Hydrological Processes, vol. 24, no. 15, pp. 2111-2124, 2010.

[32] A. C. Favre, S. E. Adlouni, L. Perreault, N. Thiemonge, and B. Bernard, "Multivariate hydrological frequency analysis using copulas," Water Resources Research, vol. 40, no. 1, pp. 1-12, 2004. 
[33] F. Serinaldi, “Analysis of inter-gauge dependence by Kendall's $\tau K$, upper tail dependence coefficient, and 2-copulas with application to rainfall fields," Stochastic Environmental Research and Risk Assessment, vol. 22, no. 6, pp. 671-688, 2008.

[34] C. Schölzel and P. Friederichs, "Multivariate non-normally distributed random variables in climate research \&amp; ndash; introduction to the copula approach," Nonlinear Processes in Geophysics, vol. 15, no. 5, pp. 761-772, 2008.

[35] P. Laux, S. Vogl, W. Qiu, H. R. Knoche, and H. Kunstmann, "Copula-based statistical refinement of precipitation in RCM simulations over complex terrain," Hydrology and Earth System Sciences, vol. 15, no. 7, pp. 2401-2419, 2011.

[36] R. L. Wilby, C. W. Dawson, and E. M. Barrow, "SDSM-A decision support tool for the assessment of regional climate change impacts," Journal of Environmental Modeling and Software, vol. 17, no. 2, pp. 147-159, 2002.

[37] Y. B. Dibike and P. Coulibaly, "Hydrologic impact of climate change in the Saguenay watershed: comparison of downscaling methods and hydrologic models," Hydrology, vol. 307, no. 1-4, pp. 145-163, 2005.

[38] C. Gordon, C. Cooper, C. A. Senior et al., "The simulation of SST, sea ice extents and ocean heat transports in a version of the Hadley Centre coupled model without flux adjustmentsflux adjustments," Climate Dynamics, vol. 16, no. 2-3, pp. 147-168, 2000.

[39] V. D. Pope, M. L. Gallani, P. R. Rowntree, and R. A. Stratton, "The impact of new physical parameterizations in the Hadley Centre climate model: HadAM3," Climate Dynamic, vol. 16, no. 2-3, pp. 123-146, 2000.

[40] A. Sklar, Fonctions der'epartition 'a n dimensionset leursmarges, Publications de l'Institut de Statistique de l'Universit'e de Paris, vol. 8, pp. 229-231, 1959.

[41] R. B. Nelsen, An Introduction to Copulas, Springer, New York, NY, USA, 2006.

[42] J. Yan, "Enjoy the joy of copulas: with a package copula," Statistical Software, vol. 21, no. 4, pp. 1-21, 2007.

[43] S. Madadgar and H. Moradkhani, "Drought analysis under climate change using copula," Journal of Hydrologic Engineering, vol. 18, no. 7, pp. 746-759, 2013.

[44] Y. Huang, J. Cai, H. Yin, and M. Cai, "Correlation of precipitation to temperature variation in the Huanghe river (yellow river) basin during 1957-2006," Journal of Hydrology, vol. 372, no. 1-4, pp. 1-8, 2009.

[45] C. Genest and L.-P. Rivest, "Statistical inference procedures for bivariate archimedean copulas," Journal of the American Statistical Association, vol. 88, no. 423, pp. 1034-1043, 1993.

[46] H. Akaike, "A new look at the statistical model identification," IEEE Transactions on Automatic Control, vol. 19, no. 6, pp. 716-723, 1974.

[47] H. Bozdogan, "Akaike's information criterion and recent developments in information complexity," Journal of Mathematical Psychology, vol. 44, no. 1, pp. 62-91, 2000.

[48] P. K. Mohammadi and D. M. Zimmer, "Copula modeling: an introduction for practitioners," Foundations and Trends in Econometrics, vol. 1, no. 1, pp. 1-111, 2005.

[49] J. T. Shiau, "Fitting drought duration and severity with twodimensional copulas," Water Resources Management, vol. 20, no. 5, pp. 795-815, 2006.

[50] N. Bezak, K. Zabre, and M. Sraj, "Application of copula functions for rainfall interception modelling," Journal of Water, vol. 10, no. 8, pp. 1-17, 2018. 

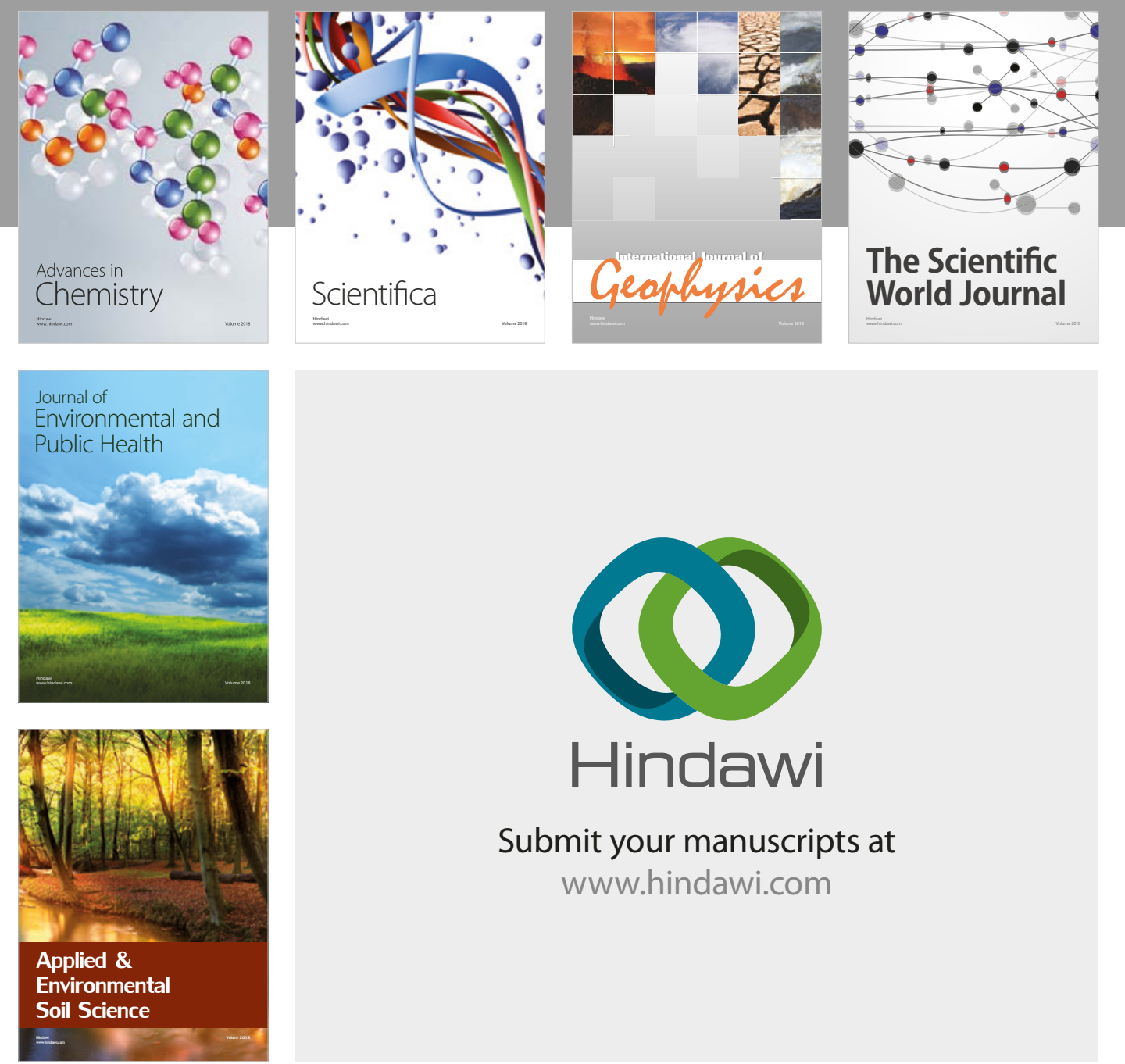

The Scientific

\section{World Journal}
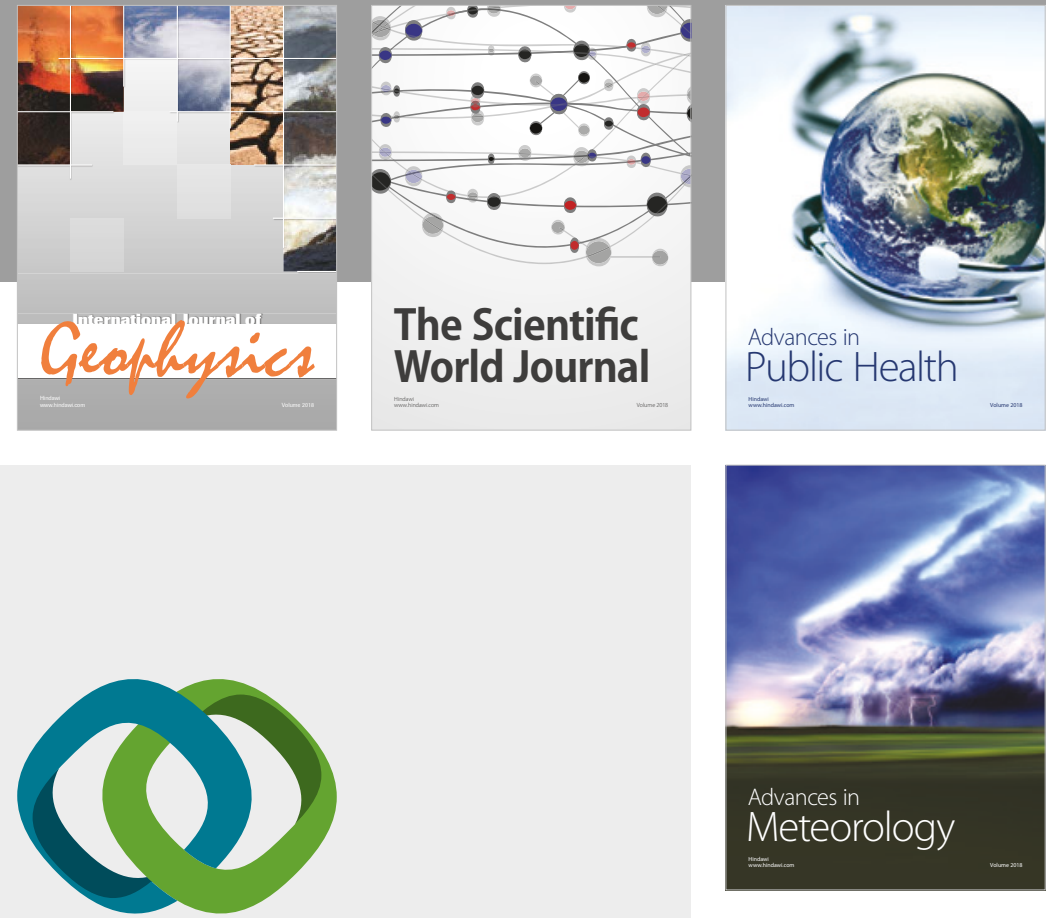

Advan

Public Health

\section{Hindawi}

Submit your manuscripts at

www.hindawi.com
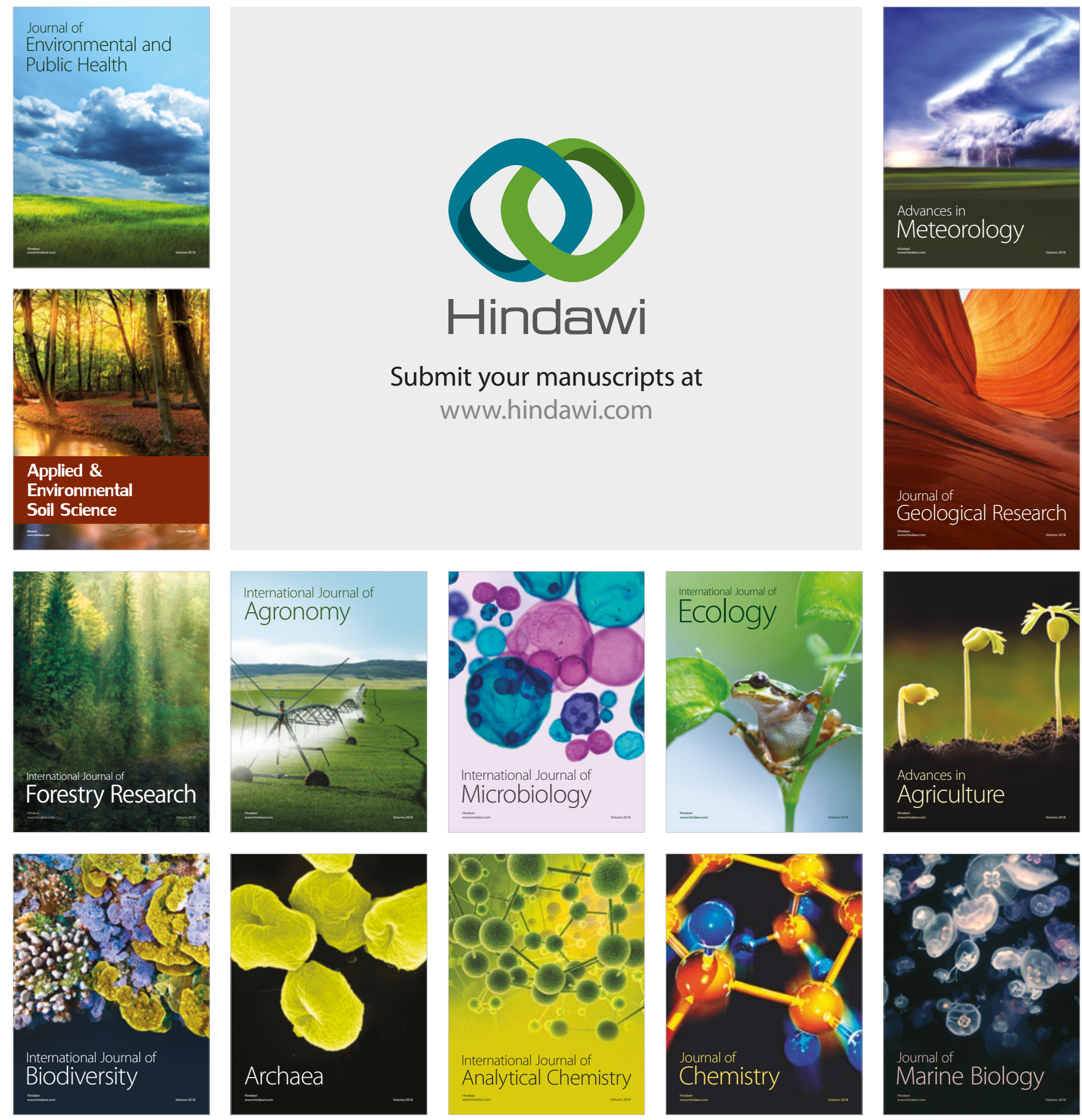